\title{
Synergetic Influence of Bismuth Oxide Nanoparticles, Cisplatin and Baicalein-Rich Fraction on Reactive Oxygen Species Generation and Radiosensitization Effects for Clinical Radiotherapy Beams
}

This article was published in the following Dove Press journal:

International Journal of Nanomedicine

\author{
Noor Nabilah Talik Sisin (ID) \\ Khairunisak Abdul Razak (D) ${ }^{2}$ \\ Safri Zainal Abidin (1D ${ }^{3}$ \\ Nor Fazila Che Mat $\mathbb{D}^{\prime}$ \\ Reduan Abdullah (D) ${ }^{1,4}$ \\ Raizulnasuha Ab Rashid (D) \\ Muhammad Afiq Khairil \\ Anuar (D) \\ Wan Nordiana Rahman (D) \\ 'Medical Radiation Programme, School of \\ Health Sciences, Universiti Sains Malaysia, \\ Kubang Kerian, Kelantan,Malaysia; \\ ${ }^{2}$ Material Engineering Programme, School \\ of Materials and Mineral Resources \\ Engineering, Universiti Sains Malaysia, \\ Nibong Tebal, Penang, Malaysia; \\ ${ }^{3}$ Oncological and Radiological Sciences \\ Cluster, Advanced Medical and Dental \\ Institute, Universiti Sains Malaysia, \\ Bertam, Penang, Malaysia; ${ }^{4}$ Nuclear \\ Medicine, Radiotherapy and Oncology \\ Department, Hospital of Universiti Sains \\ Malaysia, Kubang Kerian, Kelantan, \\ Malaysia
}

Purpose: This study aimed to quantify synergetic effects induced by bismuth oxide nanoparticles (BiONPs), cisplatin (Cis) and baicalein-rich fraction (BRF) natural-based agent on the reactive oxygen species (ROS) generation and radiosensitization effects under irradiation of clinical radiotherapy beams of photon, electron and HDR-brachytherapy. The combined therapeutic responses of each compound and clinical radiotherapy beam were evaluated on breast cancer and normal fibroblast cell line.

Methods: In this study, individual BiONPs, Cis, and BRF, as well as combinations of BiONPs-Cis (BC), BiONPs-BRF (BB) and BiONPs-Cis-BRF (BCB) were treated to the cells before irradiation using HDR brachytherapy with $0.38 \mathrm{MeV}$ iridium-192 source, $6 \mathrm{MV}$ photon beam and $6 \mathrm{MeV}$ electron beam. The individual or synergetic effects from the application of the treatment components during the radiotherapy were elucidated by quantifying the ROS generation and radiosensitization effects on MCF-7 and MDA-MB-231 breast cancer cell lines as well as NIH/3T3 normal cell line.

Results: The ROS generated in the presence of Cis stimulated the most substantial amount of ROS compared to the BiONPs and BRF. Meanwhile, the combination of the components had induced the higher ROS levels for photon beam than the brachytherapy and electron beam. The highest ROS enhancement relative to the control is attributable to the presence of $\mathrm{BC}$ combination in MDA-MB-231 cells, in comparison to the BB and BCB combinations. The radiosensitization effects which were quantified using the sensitization enhancement ratio (SER) indicate the highest value by $\mathrm{BC}$ in $\mathrm{MCF}-7$ cells, followed by $\mathrm{BCB}$ and $\mathrm{BB}$ treatment. The radiosensitization effects are found to be more prominent for brachytherapy in comparison to photon and electron beam.

Conclusion: The BiONPs, Cis and BRF are the potential radiosensitizers that could improve the efficiency of radiotherapy to eradicate the cancer cells. The combination of these potent radiosensitizers might produce multiple effects when applied in radiotherapy. The $\mathrm{BC}$ combination is found to have the highest SER, followed by the $\mathrm{BCB}$ combination. This study is also the first to investigate the effect of BRF in combination with BiONPs (BB) and $\mathrm{BC}(\mathrm{BCB})$ treatments.

Keywords: cisplatin, bismuth oxide, baicalein, radiosensitization, reactive oxygen species

\section{Introduction}

Radiotherapy (RT) is the most common type of curative and palliative treatment for all cancer patients, including breast cancer patients. ${ }^{1,2}$ Worldwide, breast cancers
Correspondence: Wan Nordiana Rahman School of Health Sciences, Universiti Sains Malaysia, Kelantan, Malaysia

Tel +60976778I I

Email wandiana@usm.my
International Journal of Nanomedicine 2020:15 7805-7823

7805 
had totaled up to 2 million new cancer cases in the year 2018, which was approximately closed to the number of lung cancers and followed by colorectal, prostate and stomach cancers. ${ }^{3}$ In particular, breast cancers are the leading causes of death among females in 103 countries. $^{3}$ The incidence rates were highest in Western and Northern Europe, as well as Australia and New Zealand. ${ }^{4}$

Clinically, the regular mode of RT for breast cancer patients is the fractionated whole breast radiation therapy, implemented for over a month. ${ }^{5}$ The current methods of RT, unfortunately, would expose ionizing radiations towards the surrounding healthy tissues with significant doses that can induce harmful complications towards the normal cells. The application of radiosensitizers to increase more radiation absorption onto the cancerous cells while sparing healthy tissue and other organs at risk are currently an active research area in RT. Goswami et al had defined four critical features of a radiosensitizer, which are (1) capable of enhancing the low radiation dose given profoundly, (2) an excellent cancer-targeting capability, (3) low toxicity and biocompatible with cells, and (4) could be rapidly cleared from the body through renal clearance mechanism. ${ }^{6}$

In the recent decade, various types of radiosensitizers have been developed such as the metallic nanoparticles (NPs), enzyme inhibitors, protein inhibitors as well as traditional Chinese herbs as the agents that could sensitize cancer cells towards radiation. ${ }^{7}$ Applications on metallic NPs in RT had shown some potentials for the further development, such as $1 \mathrm{mM}$ of gold NPs has been to be a potential dose enhancer with a given dose enhancement factor up to 25 times for an $80 \mathrm{kVp}$ x-ray energy, while $70 \mathrm{mg} / \mathrm{g}$ of bismuth oxide was estimated to enhance the dose by 18 times for ${ }^{131}$ Cs source. ${ }^{8-10}$ Several prior studies had established that gold and bismuth oxide NPs could be the radiosensitizers for some clinical radiotherapy modalities such as photon beam (6 and $10 \mathrm{MV}$ ), electron beam (6 and $15 \mathrm{MeV}$ ) and brachytherapy with iridium-192 (Ir192) source. ${ }^{1-14}$ Apart from gold and bismuth oxide NPs, platinum and superparamagnetic iron oxide NPs (SPIONs) also had the potential to be a radiosensitizer, as our previous research on the four types of NPs under $150 \mathrm{MeV}$ proton beam found to have sensitization enhancement ratio (SER) values of 1.95 to 4.93 . $^{15}$ The dendrite-shaped platinum NPs with the sizes of 29 to $52 \mathrm{~nm}$ were also discovered to cause the radiosensitization effect with SER of 1.77 to 2.31 for photon beam radiotherapy, while a smaller size of platinum NPs $(1.7 \mathrm{~nm})$ demonstrated the amplification of the effect from cobalt-60 radiation by $37 \%$. ${ }^{16,17}$

Current translational applications of NPs observed that gadolinium, SPIONs and hafnium oxide NPs had accomplished the radiosensitization effects in Phase 1 of clinical trials. ${ }^{18-20}$ Earlier, hafnium oxide NPs radioenhancer, called NBTXR3, was injected percutaneously into soft tissue sarcoma (STS) patients as a pre-operative treatment and irradiated with external beam RT. ${ }^{19}$ Adverse effect from the NPs are found to be reversible and manageable. ${ }^{19}$ Later, SPIONs (known as NanoTherm ${ }^{\circledR}$ ) and gadolinium NPs (known as AGuIX) were investigated in glioblastoma and brain metastases patients. ${ }^{18,20}$ The phase 1 clinical trial of the NanoTherm ${ }^{\circledR}$ was combined with intracavitary thermotherapy as well as image-guided RT. ${ }^{18}$ Substantial side effects were not observed throughout the therapy phase; however, a strong inflammatory reaction was developed after two to five months. ${ }^{18}$ Additionally, the AGuIX was combined with whole-brain RT for the multiple brain metastases patients after its radiosensitizing effects were confirmed in pre-clinical research and this study is still ongoing. ${ }^{20}$ However, the few clinical investigations of the NPs were only limited to the STS and brain cancer patients.

Therapeutic values of these NPs could be widened by the combination with the existing chemotherapeutic drugs. Some of the commercial drugs have been used clinically as radiosensitizers. The platinum-based clinical drug, cisplatin, is found to induce a high volume of ROS intracellularly, as well as heighten the radiosensitivity of HT-29 and SW-480 colorectal cancer cells. ${ }^{21}$ Low-dose fractionated radiation has been detected to enhance the effects of cisplatin independently of the hyper-radiation sensitivity of H-157, H460, A549, and UKY-29 lung cancer cells. ${ }^{22}$ Liu and his colleagues also had determined that radiation with the presence of cisplatin could increase cell death through apoptosis and autophagy. ${ }^{23}$

Nevertheless, the metal-based radiosensitizers hold a compromising biocompatibility and contribute to toxic effects. Alternatively, plant-derived radiosensitizers or chemotherapeutic drugs that contain effective phytochemicals are considered safer and biocompatible as compared to the conventional drugs. Natural anticancer agents from plants such as Oroxylum indicum (OI) plant extract, curcumin, usnic acid, and Dictyota dichotoma brown alga extract are discovered to have radiosensitizing or radioprotective properties towards ionizing radiations. $^{24-29}$ Previously, Rahman et al have indicated 
that OI leaves extract could enhance the radiation dose of $6 \mathrm{MV}$ and $10 \mathrm{MV}$ photon beams on HeLa cancer cells. $^{30}$ The OI leaves extract provides a newly isolated baicalein-rich fraction (BRF) that has been validated to have anti-cancer, anti-virus and anti-oxidant properties. ${ }^{31,32}$ While OI leaves extract has been proven to hold the radiosensitizing properties, it is still unknown whether the BRF from the same plant gives the similar effects, as the composition of the compounds from the BRF was different from the OI leaves extracts. Thus, it is interesting to investigate the natural BRF effects with ionizing radiations of clinical RT beams on cancer and normal cells, in comparison to commercial drug and NPs.

Most of the previous works on NPs emphasized on the dose enhancement by individual NPs as well as a combination with commercial drug only, but in the present study, three components; bismuth oxide nanoparticles (BiONPs), cisplatin drug (Cis), and a baicalein-rich fraction (BRF) are applied as the prospective radiosensitizers. In the cancer treatments, triple drug-based chemotherapy research is common as it was clinically proven to improve the therapeutic responses than a combination of two drugs. ${ }^{33,34}$ Each drug would attack the cancer cells through different mechanisms and hence produce the optimal outcome with the RT. The mechanism of cell death by ionizing radiation also involved all physical, chemical, and biological effects. ${ }^{35}$ Byproducts of radiation interaction are the generation of reactive oxygen species (ROS), which includes both radical and non-radical species. The ROS was induced due to the breakage of the chemical bonds of tissue molecules, especially water molecules after the irradiation, leading to DNA, RNA, and protein damages. ${ }^{1,36}$ Following the induction of the high amount of ROS, it could initiate the cell apoptosis and cell cycle redistribution. ${ }^{37,38}$ The presence of radiosensitizers could amplify the ROS production.

In this present study, the primary objectives are to quantify synergetic effects induced by BiONPs, Cis and BRF natural-based agent on the ROS generation and radiosensitization effects under irradiation of clinical radiotherapy beams of photon, electron and HDRbrachytherapy. The combination of the three individual components may able to achieve the aforementioned four critical features of the radiosensitizer. This study is the first to investigate the combination of the three components, especially involving the natural compound BRF in combination with the BiONPs and Cis for the clinical RT beams. This study also evaluates whether the triple combination of prospective radiosensitizers was more successful than the double combination or single radiosensitizer in stimulating ROS generation, their interactions, and radiosensitizing effects on breast cancer and fibroblast cells.

\section{Materials and Methods BiONPs, Cis and BRF Preparations}

Bismuth oxide nanoparticles (BiONPs) were synthesized using hydrothermal methods as in the established processes. $^{39}$ The synthesis was started with a dilution of $5.82 \mathrm{~g}$ bismuth (III) nitrate pentahydrate $\left(\mathrm{Bi}\left(\mathrm{NO}_{3}\right)_{3} .5 \mathrm{H}_{2} \mathrm{O}\right)$ and $1.7 \mathrm{~g}$ sodium sulfate $\left(\mathrm{Na}_{2} \mathrm{SO}_{4}\right)$ in distilled water. During the stirring process, 2.88 g sodium hydroxide $(\mathrm{NaOH})$ was added slowly into the beaker. Yellow precipitates were formed after 45 minutes of stirring. The suspension was transferred into a Schott bottle and sealed to undergo hydrothermal reactions at $60^{\circ} \mathrm{C}$. After 10 minutes, the bottle containing the yellow precipitates was left to cool at room temperature and centrifuged in a $50 \mathrm{~mL}$ tube with deionized water before washing twice with ethanol. Lastly, the precipitates were filtered and dried in an incubator at a temperature of $80^{\circ}$ C. The product was the bismuth oxide particles in the nano-sized form of $60 \mathrm{~nm}$ in diameter and rod-shaped. The BiONPs were dispersed in Dulbecco's Modified Eagle Media (DMEM) and stored at $4^{\circ} \mathrm{C}$ for the in vitro studies. In a previous study, we have conducted in vitro cytotoxic effect which concluded the $0.5 \mathrm{mM}$ as the biocompatible concentration used in this study. ${ }^{13}$

Cisplatin (Cis) (Tokyo Chemical Industry) was prepared as $41.7 \mu \mathrm{M}$ in dimethyl sulfoxide (DMSO) (Fisher Scientific) solvent and stored at $-20^{\circ} \mathrm{C}$. Cis was treated onto the cells to a final concentration of $1.30 \mu \mathrm{M}$ within the well, based on the cytotoxicity assay in our recently published work. $^{12}$

Baicalein-rich fraction (BRF) was targeted and isolated from the extract of Oroxylum indicum plant leaves using preparative thin layer chromatography as the methods published by our team previously. ${ }^{32}$ It was verified using high-performance liquid chromatography that $75 \%$ of the BRF is the baicalein compound. ${ }^{32}$ In this study, the BRF was dissolved in the DMSO solution and stored at $-20^{\circ} \mathrm{C}$ for future use. The final concentration of $2.71 \mu \mathrm{g} / \mathrm{mL}$ of 
BRF was chosen after a preliminary study, as it could cause a $25 \%$ inhibition concentration (unpublished data). ${ }^{40}$

\section{Cell Culture}

Human breast cancer cell lines (MCF-7 and MDA-MB -231) and a mouse fibroblast cell line (NIH/3T3), which commercially purchased from $\mathrm{ATCC}^{\circledR}$, were used in this work. The MCF-7 and MDA-MB-231 represented two breast cancer cell lines with different subtypes. ${ }^{41}$ The $\mathrm{NIH} / 3 \mathrm{~T} 3$ cells were selected as normal cells model because they are widely used in biomaterial cytotoxicity testing due to their characteristics, infinite life span, easily handled, and robust. ${ }^{42,43}$ The cells were grown in flasks of $25 \mathrm{~cm}^{2}$ with Dulbecco's Modified Eagles Medium (DMEM, Gibco, USA), supplemented with $5 \%$ of fetal bovine serum (FBS) (Gibco, USA) and 1\% penicillinstreptomycin (Gibco, USA), before being trypsinized and re-seeded into 96-well plates (for ROS study) or prepared in $0.2 \mathrm{~mL}$ tube for radiosensitization study. The treatment details are presented in Table 1.

\section{Cell Irradiation Set Up}

The normal fibroblast cell line (NIH/3T3) and breast cancer cell lines (MCF-7 and MDA-MB-231) were prepared in suspensions in a $0.2 \mathrm{~mL}$ tube at a density of $1 \times 10^{5}$ cells per $\mathrm{mL}$ before being treated with each treatment component, as the results in Table 1. The treatment components were cocultured with the cells for a maximum of 1 hour before irradiation with the total maximum volume of $150 \mu \mathrm{L}$ of cell suspension. The cell samples were positioned on top of tissue-equivalent water phantom, as depicted in Figure 1. A superflab bolus was laid on the top of cell sample tubes with a thickness of $1.4 \mathrm{~cm}$ for the electron beam and $1.5 \mathrm{~cm}$ for the photon beam and brachytherapy for the dose build-up. Radiation doses were verified using Gafchromic $_{\mathrm{TM}}$ EBT3 films, which were underneath the cell sample tubes. The samples were exposed to $6 \mathrm{MV}$ photon and $6 \mathrm{MeV}$ electron beams from a medical linear accelerator (Siemens Primus) with radiation doses ranging from 0 to $10 \mathrm{~Gy}$ of single fractions.

The brachytherapy irradiation was performed with Iridium-192 source of $0.38 \mathrm{MeV}$ gamma-ray emitter using Microselectron HDR Brachytherapy (Nucletron Corp, Columbia, Maryland). Typically, the routine clinical schedules of breast cancer radiotherapy involved 2-3 Gy fractionation (external beam radiation) for several weeks as to give times for the healthy normal cells to recover. ${ }^{44-46}$ Irradiation dose applied for brachytherapy irradiation were
0,3 , and 6 Gy. All cell irradiation experiment setups are depicted in Figure 1 and performed at Nuclear Medicine, Radiotherapy and Oncology Department, Hospital Universiti Sains Malaysia.

\section{Reactive Oxygen Species Measurement}

In the ROS measurement, approximately $5 \times 10^{4}$ cells per $\mathrm{mL}$ of MCF-7 and MDA-MB-231 cell lines were grown in 96wells plates and incubated until the confluency reached $90 \%$. The cells were incubated with fresh cell culture media before treatment with single or combinations of BiONPs, BRF, and Cis, as tabulated in Table 1.

Approximately 1 hour before irradiation, the cells were exposed to $2^{\prime}, 7^{\prime}$ - dichlorodihydro-fluorescein diacetate $\left(\mathrm{DCH}_{2}\right.$ F-DA, Sigma-Aldrich) with a final concentration of $9 \mu \mathrm{M}$ per well. It was recommended to use a concentration of lower than $25 \mu \mathrm{M} .{ }^{47} \mathrm{DCH}_{2} \mathrm{~F}-\mathrm{DA}$ is a fluorometric dye and is widely used to test the presence of ROS in cells quantitatively. ${ }^{47-49}$ This dye would be internalized into cellular cytoplasm and undergone a hydrolyzation process to be retained in the cells. ${ }^{50,51}$ The presence of ROS within the cells would oxidize the products into $2^{\prime}, 7^{\prime}$-dichlorofluorescein (DCF) that has fluorescent properties. ${ }^{51}$ Thus, the generation of intracellular ROS caused by any stimulus could be quantified by the detection of the highly fluorescent DCF.

The immediate ROS reading before (control) and after (0 hours) irradiation $(0,3$, and 6 Gy doses) were measured, without removing any compounds, using spectral scanning multimode reader (Varioskan Flash, Thermo Scientific) at $485 \mathrm{~nm}$ excitation and $530 \mathrm{~nm}$ emission. This protocol is a quantitative method as the measurements were expressed in numbers, the dimension of the number was computed from the intensity of the DCF fluorescence, and no microscopic observation was made. ${ }^{52-54}$ The percentage of ROS

Table I Treatment Components for ROS and Radiosensitization Effect Measurement

\begin{tabular}{|l|l|}
\hline Treatment & Components \\
\hline Negative & No treatment (cells only) \\
Control & \\
Positive & 3 and 6 Gy of radiation doses by the 3 clinical RT \\
Control & sources \\
BiONPs & $0.5 \mathrm{mM}$ of $60 \mathrm{~nm}$ of BiONPs \\
Cis & $1.30 \mu \mathrm{M}$ of Cis \\
BRF & $2.71 \mu \mathrm{mL}$ of BRF \\
BB & $0.5 \mathrm{mM} \mathrm{BiONPs}+2.7 \mathrm{I} \mu \mathrm{g} / \mathrm{mL} \mathrm{BRF}$ \\
BC & $0.5 \mathrm{mM} \mathrm{BiONPs}+1.30 \mu \mathrm{M}$ Cis \\
BCB & $0.5 \mathrm{mM} \mathrm{BiONPs}+1.30 \mu \mathrm{M}$ Cis $+2.7 \mathrm{I} \mu \mathrm{g} / \mathrm{mL} \mathrm{BRF}$ \\
\hline
\end{tabular}




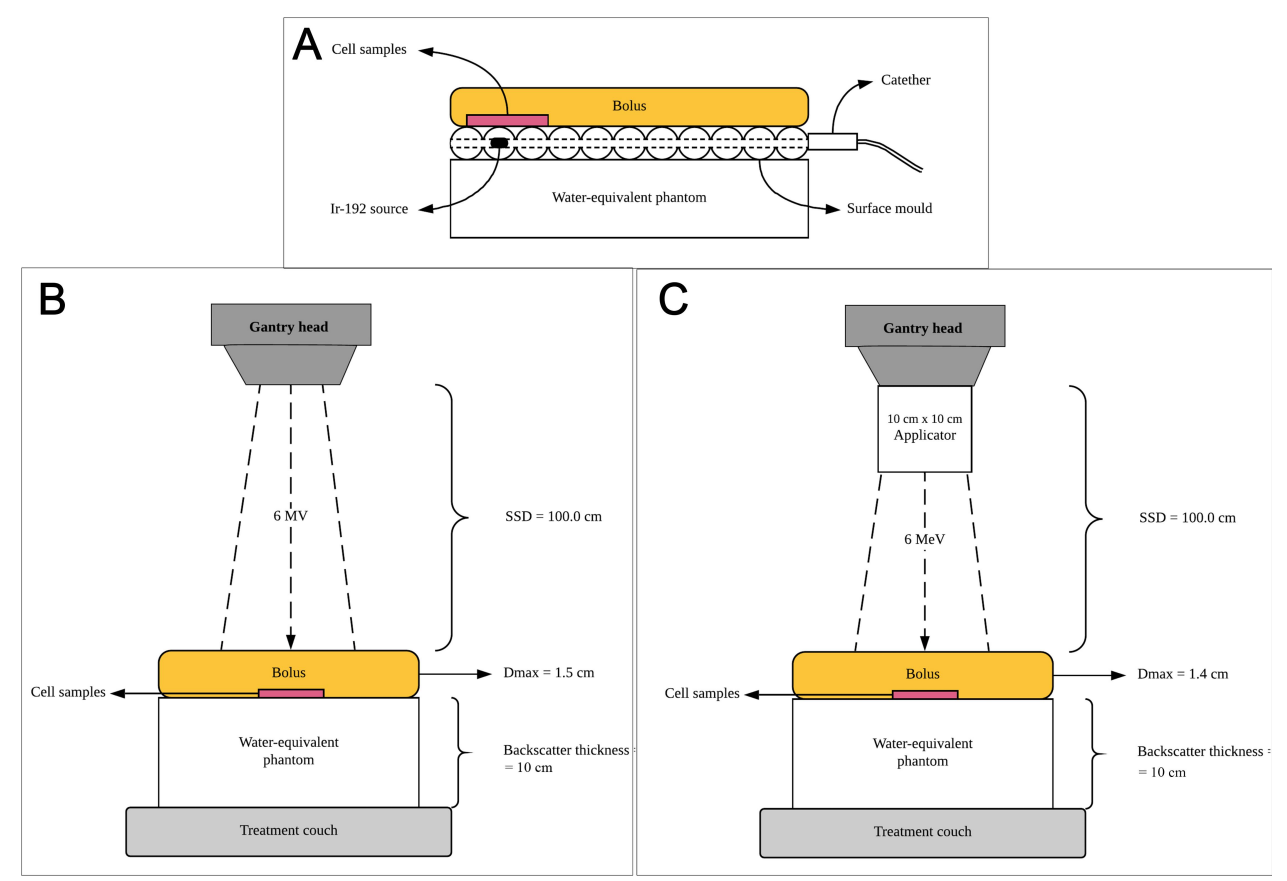

Figure I The schematic diagrams of irradiation setup for each source and beam: (A) brachytherapy (B) photon, and (C) electron. Abbreviations: $\mathrm{D}_{\max }$, depth of maximum dose; SSD, source-to-surface distance; $\mathrm{mM}$, millimolar.

generation relative to the overall initial ROS level was calculated as Equation 1.

$\%$ of $\operatorname{ROS}=$

$$
\frac{\text { DCF value of treatment }}{\text { DCF value of control for 0Gy before irradiation }} \times 100
$$

The percentage of ROS generation was then interpreted for their types and potential interactions for the $\mathrm{BB}$ and $\mathrm{BC}$ combinations based on the individual components, according to a conceptual approach by Piggott et al. ${ }^{55}$ This modelling is a system that classifies the addition, synergism or antagonism interactions based on the magnitude of two response variables (for examples, "a" and "b"), and the interaction or cumulative effect of the " $a+b$ " combination. The probable interactions for $\mathrm{BCB}$ combination are not interpreted as this concept is limited to the combination of two components only.

\section{Clonogenic Survival Assay}

The irradiated cell samples in the vials were immediately transferred into 6- well plates for clonogenic assay. A total of $1.5 \mathrm{~mL}$ of new media were added into each well. The plates were incubated for 10 days for MDA-MB-231 cells and 5 days for MCF-7 cells as well as NIH/3T3 cells ${ }^{12}$ (without changing the media). After the incubation period, the cells media were discarded and the cells were washed with phosphate buffer saline. The cells were then fixed in cold methanol for 30 minutes prior to staining process with crystal violet solution for 1 hour. Later, the cells were washed with tap water and left to dry at room temperature. The stained cell colonies were scanned using a flatbed scanner to be counted and analyzed using ImageJ software. ${ }^{56}$ The percentage of the area covered by the stained cells were measure and counted.

\section{Cell Survival Analysis}

The cell survivals were analysed using survival fraction (SF). The SF was calculated as shown in Equation 2.

$$
\mathrm{SF}=
$$

Percentage of the stained area of irradiated cells colonies Percentage of the stained area of control cell colonies

OriginPro 2018 software was used to plot the SF curves, employing the linear-quadratic (LQ) model, which is a gold standard in clinical RT. The parameters from the LQ formula given by Equation 3 were analyzed, in which $\mathrm{S}$ is the survival fraction, while $\mathrm{D}$ is the dose (Gy).

$$
S=\exp ^{-(\alpha \mathrm{D}+\beta \mathrm{D} 2)}
$$

The model is represented by the linear component [exp $(-\alpha D)$ ], which is designated for a single hit to the 
double-strand of DNA breakage and a quadratic component $[\exp (-\beta D 2)]$ which denoted the double hits that induce double-strand damage of the chromosomes. ${ }^{12,13}$ The sensitization enhancement ratio (SER) was extrapolated from the LQ graph fittings. The values indicated the radiosensitization effect by each treatment component and were calculated using the formula as in Equation 4.

$\mathrm{SER}=$

Dose at $50 \%$ of cells survived in the control Dose at $50 \%$ of cells survived with treatment

\section{Statistical Analysis}

All data were stated as the mean \pm standard error of the mean (SEM). The graphs and statistical tests were conducted using OriginPro 2019 software (OriginLab Corporation, US). Three-way ANOVA was used to interpret the interactions between the variables, and Bonferroni post-hoc test was also employed.

\section{Results}

\section{Intracellular ROS Induced by Radiation with BiONPs, Cisplatin or BRF Individually}

The ROS generations by the individual effect of each BiONPs, Cis, and BRF, as illustrated in Figure 2. The graphs for each irradiation type imply that percentages of ROS generated by photon beam are higher than brachytherapy and electron beam. Notably, the presence of Cis had stimulated the most substantial amount of ROS compared to the BiONPs in both breast cancer cell lines. While the magnitude of ROS triggered was less in brachytherapy compared to photon and electron beams, the gap of the ROS produced in the presence of the Cis as compared to the control was always significant in brachytherapy. Additionally, the percentage of ROS formed in the presence of BRF was higher than the control for brachytherapy but lower than the control for photon and electron beams.

\section{Intracellular ROS Induced by Radiation with $\mathrm{BB}, \mathrm{BC}$, and $\mathrm{BCB}$ Combinations}

The ROS generated among the combinations of $\mathrm{BB}, \mathrm{BC}$, and $\mathrm{BCB}$ are illustrated in Figure 3. Among the BB, BC, and $\mathrm{BCB}$ combinations, the highest percentage of ROS $(6779 \%)$ obtained after irradiation with 6 Gy dose was attributable to the presence of $\mathrm{BC}$ in MDA-MB-231 cells after photon beam therapy (Figure 3B), followed closely by HDR brachytherapy (Figure 3A). Meanwhile, the lowest ROS percentage (3190\%) after irradiation with 6 Gy dose was caused by the presence of BB in MCF-7 cells after the HDR brachytherapy. Most data resulted from $3 \mathrm{~Gy}$ and $6 \mathrm{~Gy}$ irradiation doses illustrated a similar pattern in which the ROS in the presence of $\mathrm{BC}$ is the highest, followed by $\mathrm{BCB}$, and lastly, $\mathrm{BB}$ for each type of beams. However, a few results show that the ROS percentage of the positive control cells were more elevated or comparable to the $\mathrm{BB}$ and $\mathrm{BCB}$ treatments during photon (6 Gy) and electron (both $3 \mathrm{~Gy}$ and 6 Gy, Figure 3C) beams.

As the $\mathrm{BC}$ combination was observed to induce the highest ROS enhancement, the comparisons of the BC combination treatment based on the beams' quality on both cancer cells and for 0,3 and 6 Gy of radiation doses are illustrated in Figure 3D. Generally, different types of cells and radiation doses would significantly influence the ROS generation $(\mathrm{p}<0.05)$. However, the overall ROS effects between the HDR brachytherapy with Ir-192, and 6 MV photon beam in the presence of the $\mathrm{BC}$ combination were not significantly different $(p>0.05)$. At 6 Gy of dose, there is also no significant difference in the ROS induced between the photon and electron beams ( $p>0.05$ ).

In order to understand the possible interactions (synergism, antagonism, or additive effect) among the individual components for the combination treatments of $\mathrm{BB}$ and $\mathrm{BC}$, the conceptual modelling from Piggott et al's work was conducted. ${ }^{55}$ Figure 4 presents two types of interactions which might transpire for the ROS production after 6 Gy of irradiation doses; (A) double-positive interaction, in which the level of ROS responses by the individual BiONPs, Cis or BRF were higher than the responses in the Control, and (B) opposing interaction, in which the magnitude of ROS responses in the Control was higher than one of the individual BiONPs and BRF components.

Based on the two categories, the notions of synergism, antagonism or additive effects were specified to address the possible ROS processes in the presence of the $\mathrm{BC}$ and BB treatment components. Additive effects were predicted in both breast cancer cells during the brachytherapy, photon and electron beams irradiations with the $\mathrm{BC}$ combination (BC (1)). Additionally, the positive antagonism effect could also possibly occur in both cancer cells during the brachytherapy in the presence of $\mathrm{BB}$ combination (BB (2)). Apart from that, the presence of $B B$ combination in the MDA-MB-231 cells during both photon and electron beam irradiations might prompt the negative synergism 

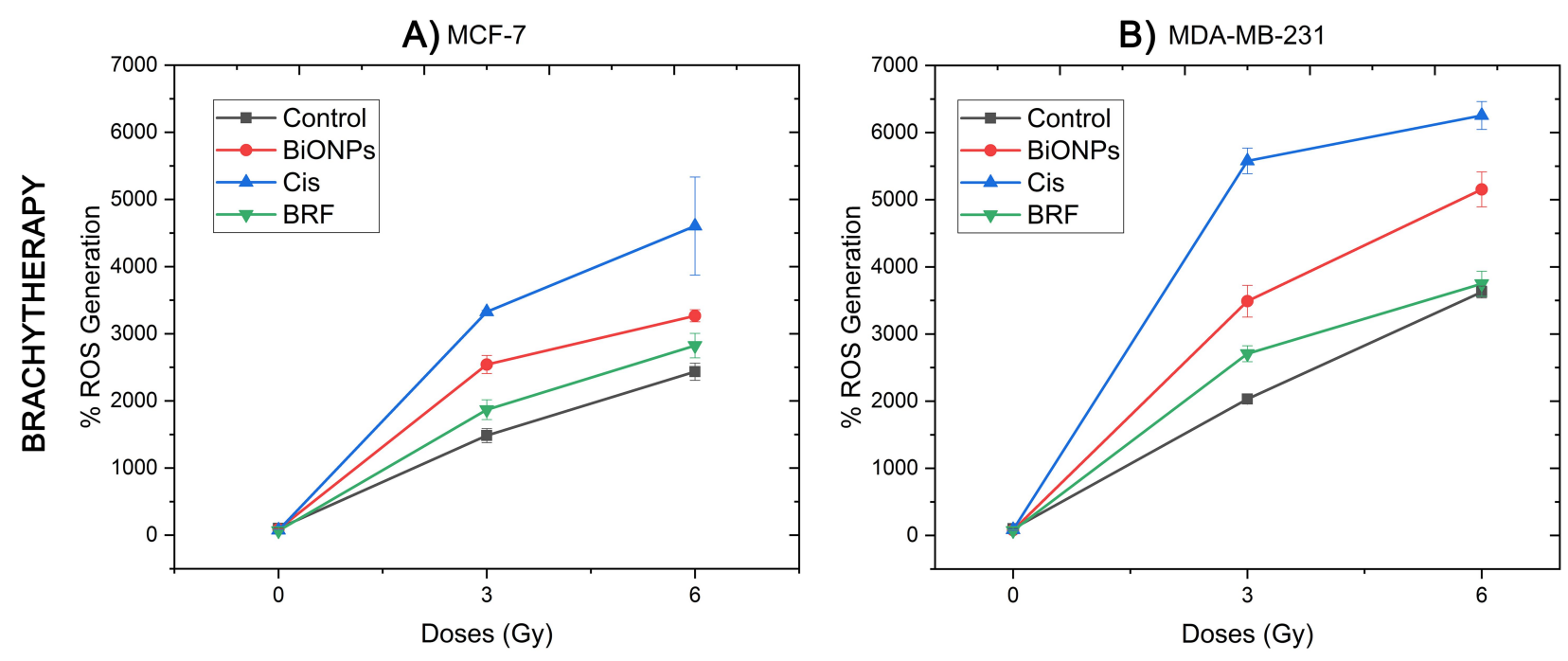

C) MCF-7
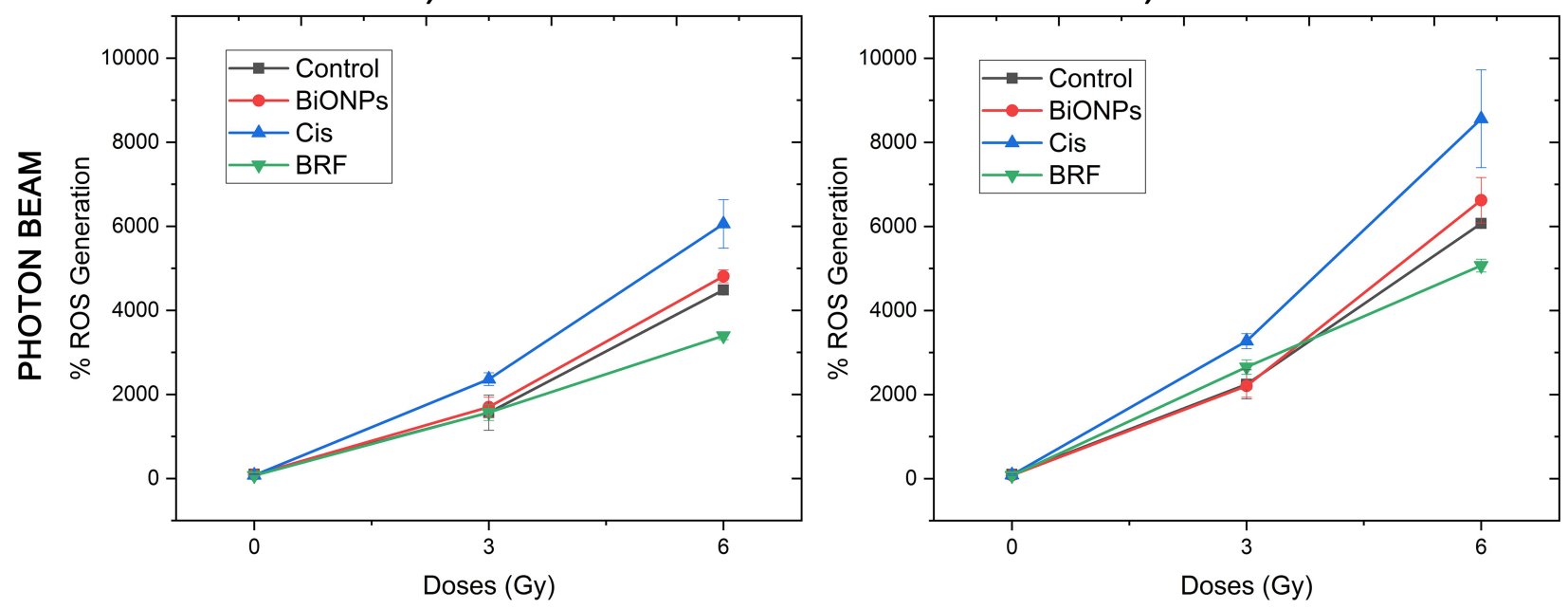

E) $\mathrm{MCF}-7$

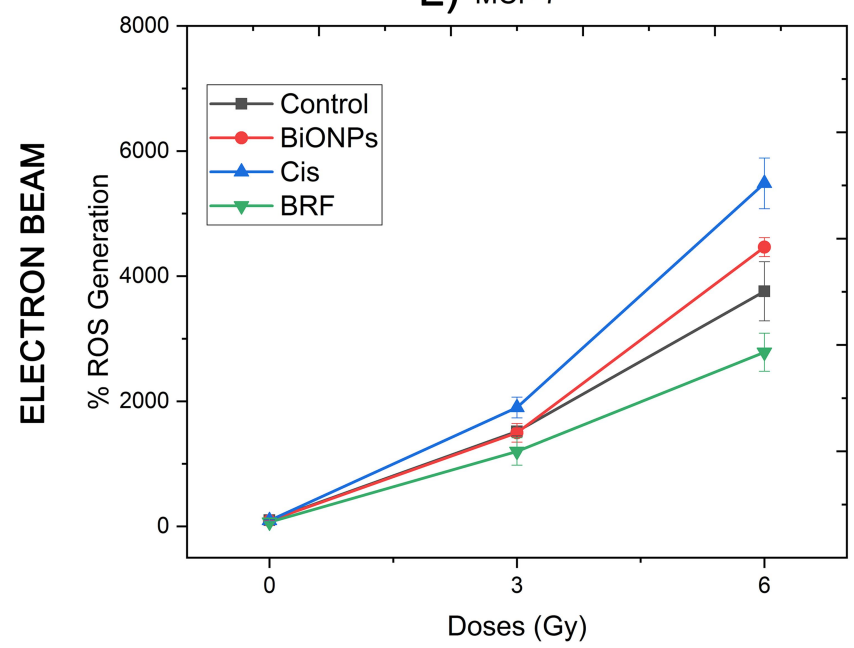

F) MDA-MB-231

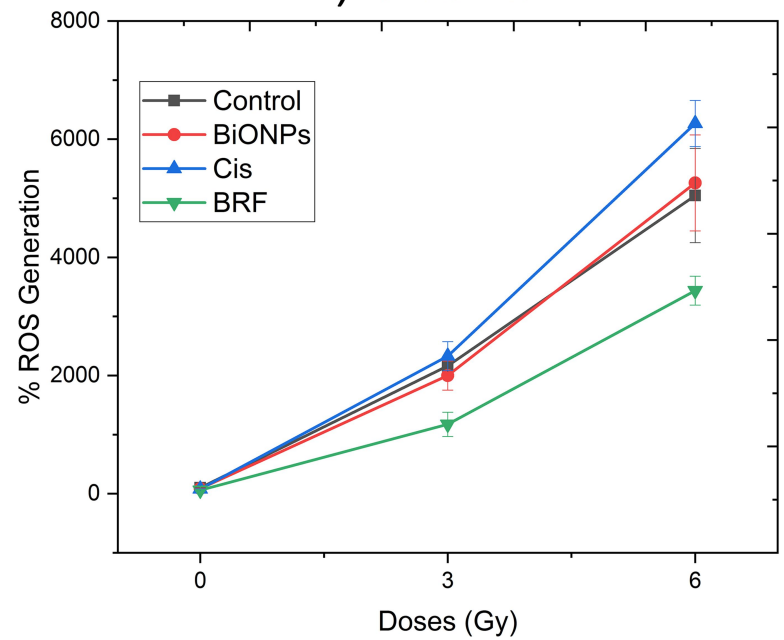

Figure 2 Percentage of ROS generation in MCF-7 and MDA-MB-23I cells in brachytherapy (A, B), photon beam (C, D), and electron beam (E, F) in the presence of individual BiONPs, Cis and BRF in comparison to control. All values after each irradiation dose (0,3, and 6 Gy) are calculated against the control value of each cell line immediately before irradiation.

Notes: Error bars represent the standard error of the mean (SEM). The results of individual control, BiONPs and Cis for brachytherapy were published in our previous work. $^{12}$

Abbreviations: BiONPs, bismuth oxide nanoparticles; Cis, cisplatin; BRF, baicalein-rich fraction. 

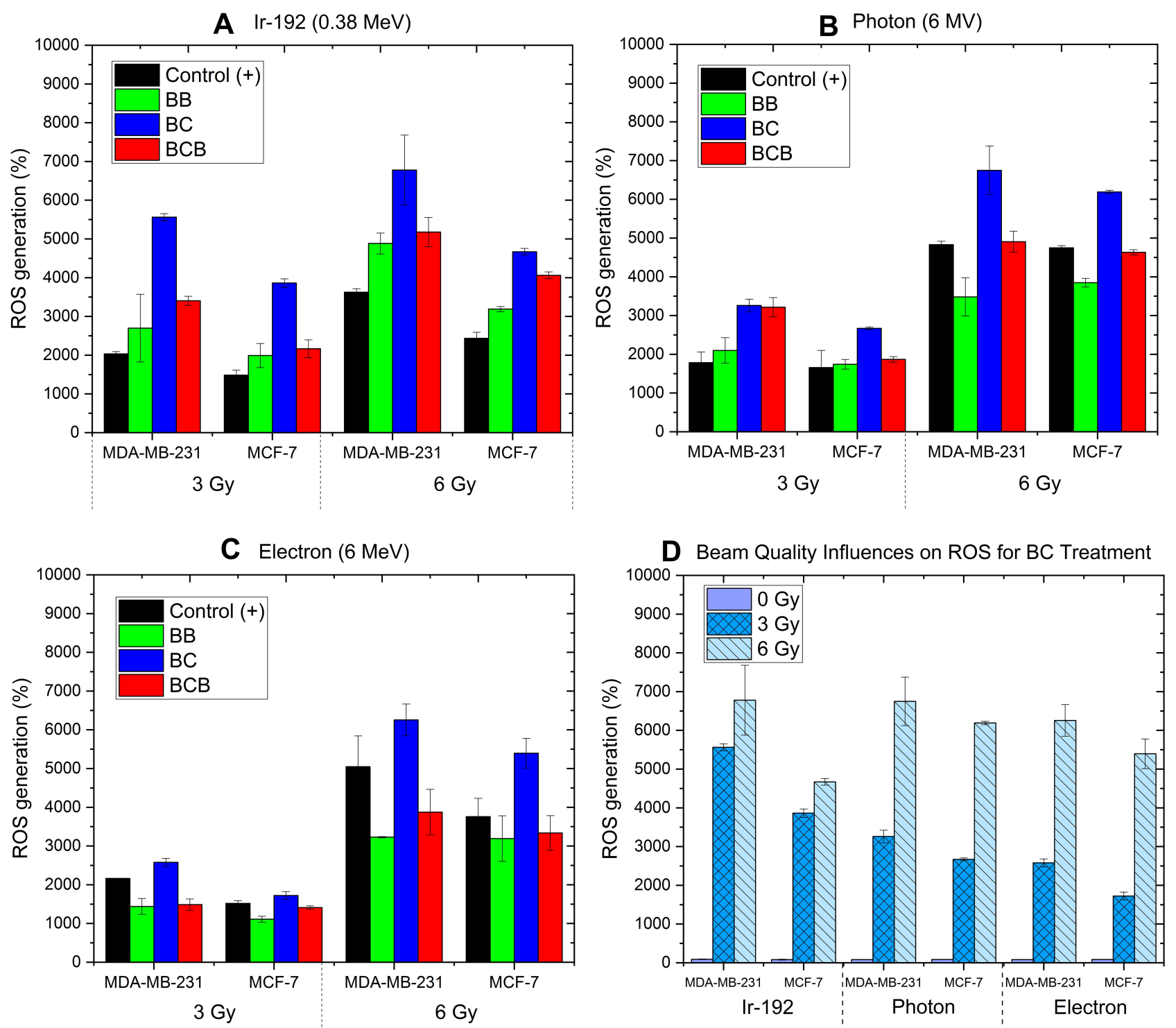

Figure 3 Percentage of ROS generation in the presence of BB, BC, as well as BCB combinations, in comparison to the negative control (before irradiation time) at doses of 3 and 6 Gy on MDA-MB-23I cells and MCF-7 cells under irradiation of (A) HDR brachytherapy Ir-192, (B) photon beam and (C) electron beam. (D) Sum-up of the ROS generation induced in the presence of $B C$ combination for all the radiation beams.

Notes: Error bars represent the standard error of the mean (SEM). Data for the part (D) were tested against 3-way ANOVA with Bonferroni post-hoc test. The results of $\mathrm{BC}$ combination for brachytherapy only were published in our previous work. ${ }^{22}$

Abbreviations: Ir, iridium; BiONPs, bismuth oxide nanoparticles; Cis, cisplatin; BRF, baicalein-rich fraction; BB, BiONPs-BRF combination; BC, BiONPs-Cis combination; $\mathrm{BCB}, \mathrm{BiONPs-Cis-BRF}$ combination.

effects (BB (3)). Meanwhile, positive antagonism could also happen in the MCF-7 cells for both photon and electron beam irradiation by the opposing interaction (BB (4)). Overall, the most favorable interaction was the additive effect by $\mathrm{BC}(1)$.

\section{Radiosensitization Effects Induced by $\mathrm{BB}, \mathrm{BC}$, and $\mathrm{BCB}$ Combinations}

The cells survival curves for $\mathrm{BB}, \mathrm{BC}$, and $\mathrm{BCB}$ treatments for brachytherapy, photon and electron beam irradiations in MCF-7, MDA-MB-231, and NIH/3T3 cells are displayed in Figure 5. The radiosensitization effects are shown in all cell lines with the $\mathrm{BC}$ treatment dominated as the most effective to lower the cells survival in MCF-7 and MDA-MB-231 cancer cells. Meanwhile, the NIH/3T3 cells are profoundly affected by $\mathrm{BCB}$ treatments in both radiation beams.

The sensitization enhancement ratio (SER) quantified for the $\mathrm{BB}, \mathrm{BC}$, and $\mathrm{BCB}$ treatments irradiated with the three types of clinical RT beams in three types of cell lines 
A Double Positive Interaction

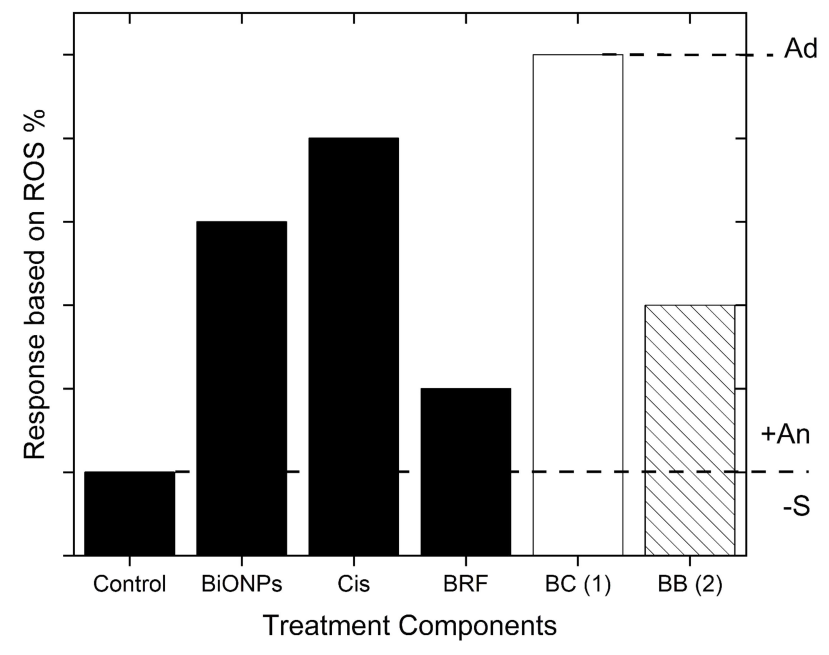

B Opposing Interaction

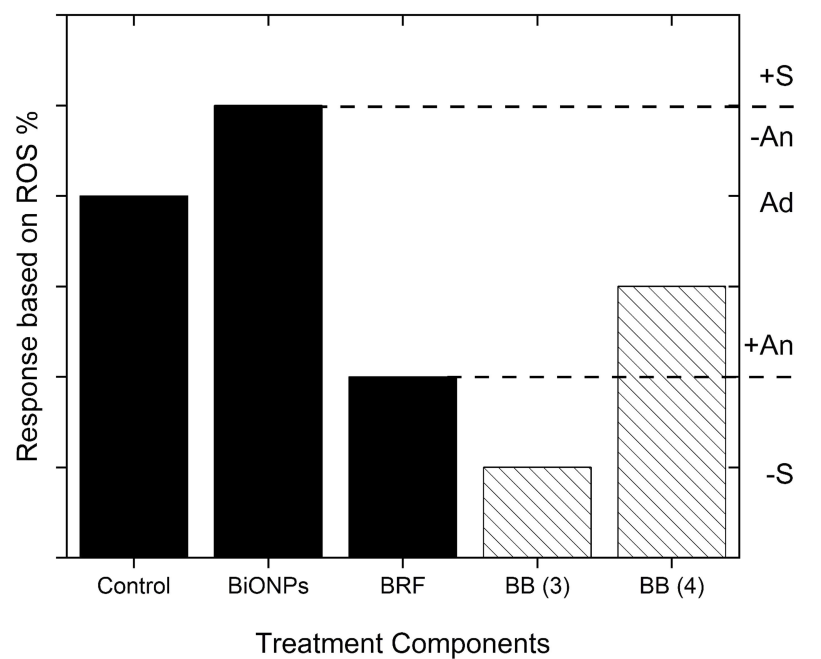

Figure 4 Conceptual modelling of the probable interactions for BC and BB combinations based on the ROS generation responses. In relative to the control, the interactions could be categorized into $(\mathbf{A})$ double-positive and $(\mathbf{B})$ opposing interactions. The interactions are further classified into negative synergism (-S), positive antagonism (+An), additive (Ad), negative antagonism (-An), and positive synergism $(+S)$. The bracketed numbers $(I)$ to $(4)$ referred to the number of the interaction which might ensue for the $\mathrm{BC}$ (white bar) and BB (bars with lines) combination treatments.

Notes: The $\mathrm{X}$-axis is the treatment component, while the $\mathrm{y}$-axis is the level of responses from the treatments (in this case, \% of ROS production). The interaction models are modified from Piggott et al. ${ }^{55}$ There is another category; double negative interaction, in which the level of response by the Control is higher than responses by both individual components, but it may not happen in the present study.

Abbreviations: BiONPs, bismuth oxide nanoparticles; Cis, cisplatin; BRF, baicalein-rich fraction, BB, BiONPs-BRF combination; BC, BiONPs-Cis combination.

are tabulated in Table 2. It is observed that most of the treatment combinations resulted in the SER value of more than 1, including in NIH/3T3 normal cell line. Apart from the highest SER value of 4.29 observed from BC combination for brachytherapy, which had been discussed in our previous work, ${ }^{12}$ the leading radiosensitization effects were elicited by the BC for the electron beam (SER of 2.98 ) in the MCF-7 cell line. Photon beam irradiation with the presence of $\mathrm{BC}$ also stimulates the radiosensitization effects with SER of 2.37 and 2.05 in MDA-MB-231 and MCF-7 cell lines, respectively.

On the other hand, the lowest SER values of 0.97 and 1.18 were reflected by the $\mathrm{BB}$ treatments for brachytherapy in NIH/3T3 cells and MDA-MB-231 cells, respectively. All other SER values obtained during all irradiation in combination with $\mathrm{BB}$ did not exceed the values of 2 , with the maximum value of 1.80 in MCF-7 cells during $6 \mathrm{MV}$ photon beam irradiation.

Additionally, the presence of BCB during the radiations triggered eminent effects of radiosensitization in both MCF-7 and MDA-MB-231 cell lines with the SER values in the range of 1.31 to 2.61. Nevertheless, the $\mathrm{BC}$ treatments in the NIH/3T3 normal cell line could induce high SER values of 1.83, 2.04 and 2.06 for the photon beam, brachytherapy and electron beams, respectively.

\section{Discussion}

\section{Intracellular ROS Induced by Radiation with BiONPs, Cisplatin or BRF Individually}

Generally, the ROS productions after irradiation were analyzed in two sub-types of breast cancer cell lines, which might affect the responses toward NPs, drugs and radiation. MDA-MB-231 cells were more sensitive to free radical generation, and MCF-7 cells have a low degree of cell sensitivity towards the nanoparticles and drug. Han et al discovered that MCF-7 cells are more resistant than MDA-MB-231 cells because of the low level of dynamin-related protein 1 (Drp1) gene expression in former cells, which would decrease mitochondrial fission, apoptosis, and metastasis of the cells. ${ }^{57}$ The insensitivity of cells towards $\mathrm{DCH}_{2} \mathrm{~F}-\mathrm{DA}$ reagent would also be one of the factors, as such cells with a low concentration of esterase enzymes might only emit low DCF fluorescence light. ${ }^{48}$ Metastatic breast cancer cells, such as MDA-MB-231, also possessed a high amount of intracellular esterase enzymes and could enhance the rate of the probe entrance into the cells. ${ }^{58}$ While MDA-MB-231 cells are known in lacking estrogen receptor (ER), progesterone receptor (PR), and human epidermal growth factor receptor 2 (HER2) receptors, they are more aggressive and metastatic than MCF-7 cells. ${ }^{59,60}$ 

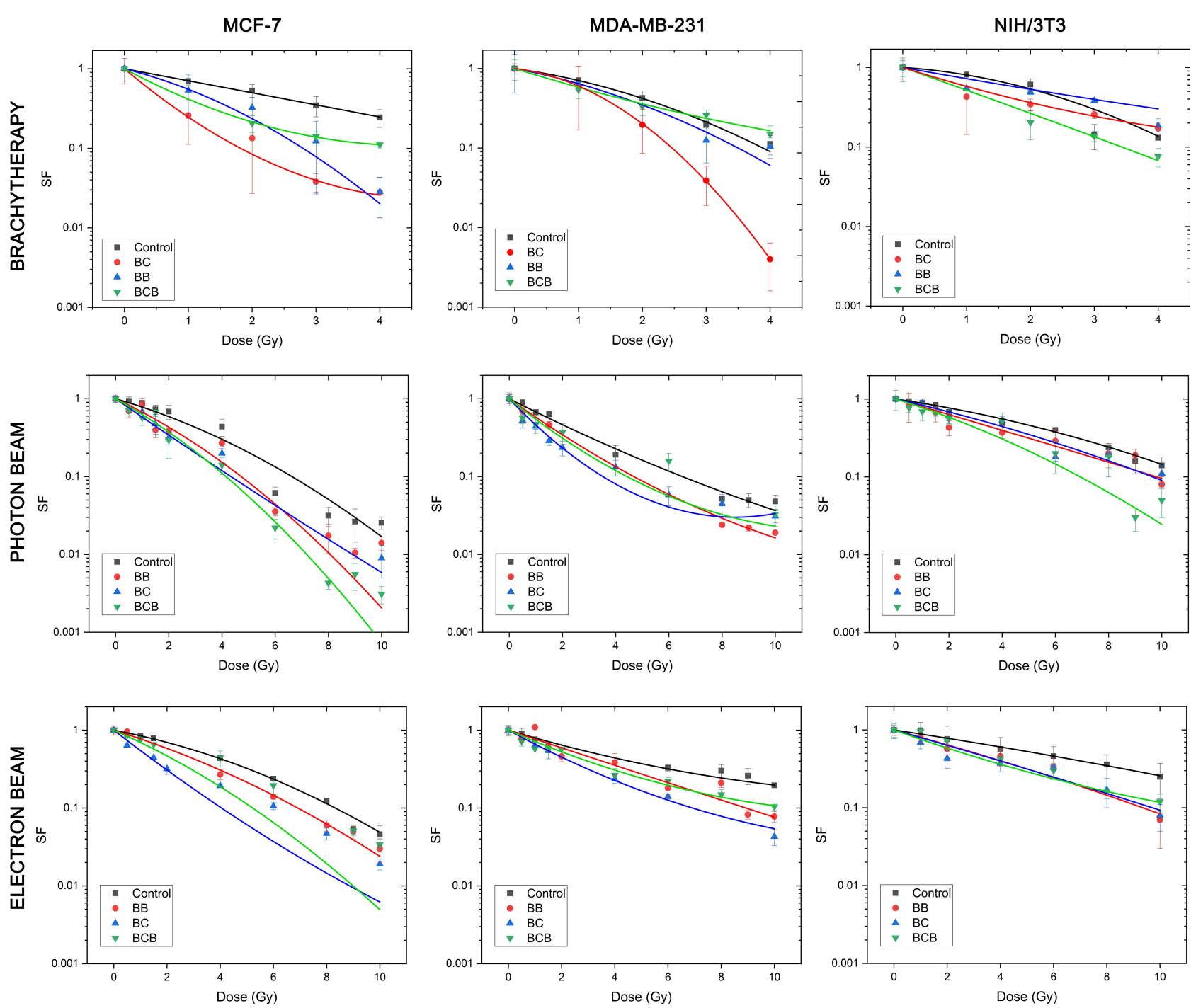

Figure 5 Cell survival curves of control, BB, BC, and BCB treatment combinations treated on MCF-7, MDA-MB-23I and NIH/3T3 cell lines irradiated with the brachytherapy, $6 \mathrm{MV}$ photon beam and $6 \mathrm{MeV}$ electron beam.

Notes: Error bars represent the standard error of the mean (SEM). The survival curve of BC combination for brachytherapy only was published in our previous work. ${ }^{12}$ Abbreviations: BB, BiONPs-BRF combination; BC, BiONPs-Cis combination; BCB, BiONPs-Cis-BRF combination.

In this study, each component comprised BiONPs, Cis, and BRF was individually tested for intracellular ROS formation. The presence of Cis during the irradiations notably showed a high level of ROS production. Fundamentally, Cis is also known as platinum diamodichloride, and $65 \%$ of its content is platinum. ${ }^{61}$ The Cis elicited the down-regulation of multidrug resistance-associated protein 1 (MRP1) expression, lowered the glutathione content, and reinforced the intracellular ROS generation, as presented by a research on a ROS generator, emodin, in T24 and J82 human bladder cancer cell lines. ${ }^{62}$ The Cis could also substantially increase the ROS, nitric oxide and lipid peroxidation levels in the kidney of mice, as well as in Cis-resistant IMC-3CR cells due to the suppression of Sestrins-1 (SESN1) protein. ${ }^{63,64}$
However, they also suggested that the SESN1 protein did not influence the radiosensitivity and viability of the cells. ${ }^{64}$ The present findings verify that the presence of Cis during irradiation might activate or subdue ROS-associated proteins within the cells as supported by the previously mentioned studies.

Subsequently, the ROS production stimulated by the presence of bismuth oxide nanoparticles (BiONPs) during the irradiations was higher than the BRF in both MCF-7 and MDA-MB-231 cell lines. Exposure of metallic nanoparticles (NPs) to and into cells had built up oxidative stress and toxicity to the mitochondria. ${ }^{65}$ The bismuth-based NPs are hypothesized to be more effective than other metallic NPs. Recent investigations had highlighted the effects of high 
Table 2 SER Values for BB, BC and BCB Treatment Combination After Irradiation with Brachytherapy, Photon and Electron Beams

\begin{tabular}{|l|l|l|l|l|}
\hline \multirow{2}{*}{ Treatments } & Sources & Brachytherapy & Photon (6 MV) & Electron (6 MeV) \\
\cline { 2 - 5 } & Cells & SER & SER & SER \\
\hline BB & MCF-7 & 1.76 & 1.80 & 1.37 \\
& MDA-MB-23I & 1.18 & 1.42 & 1.24 \\
& NIH/3T3 & 0.97 & 1.51 & 1.67 \\
\hline $\mathrm{BC}^{\prime 2}$ & MCF-7 & 4.29 & 2.37 & 2.98 \\
& MDA-MB-23I & 1.41 & 2.05 & 1.91 \\
\hline \multirow{2}{*}{$\mathrm{BCB}$} & NIH/3T3 & 1.65 & 1.46 & 1.79 \\
& MCF-7 & 2.61 & 2.09 & 1.87 \\
& MDA-MB-23I & 1.31 & 1.58 & 1.51 \\
\hline
\end{tabular}

Notes: The SER results of BC combination for brachytherapy only were published in our previous work. ${ }^{12}$

Abbreviations: BB, BiONPs-BRF combination; BC, BiONPs-Cis combination; BCB, BiONPs-Cis-BRF combination.

atomic number $(Z)$ metallic NPs such as platinum $(Z=78)$, gold $(Z=79)$, and bismuth $(Z=83) .{ }^{9,15,66}$ Hossain and $\mathrm{Su}$ also simulated the radiosensitizing effects of several diagnostic $\mathrm{X}$-ray energies among bismuth, gold as well as platinum, and stated that the irradiations which released photoelectrons and Auger electrons could cause water molecules to be lysed and formed various free radicals. ${ }^{67}$ The assumption is also particularly correct in which the ROS induced in HCT-116 cells after irradiated by proton beam in the presence of BiONPs surpassed the ROS induced in the presence of platinum, gold, or superparamagnetic iron oxide NPs. ${ }^{15}$ Although the physical interaction of the proton beam with cells is disparate from the clinical beams in the present study, the authors also implied that ROS production was firmly related to the radiosensitization effect and found that BiONPs could produce the highest SER among other NPs tested. ${ }^{15}$ Other bismuth-based NPs such as folic acid (FA) modified bismuth sulfide NPs, folate-inserted RBC membranes-coated bismuth NPs, and 5-Aminolevulinic acid-FAconjugated BiONPs, which were tested against X-ray and photodynamic irradiations, also showed the enhancement of ROS levels relative to respective controls. ${ }^{68-70}$

Even though bismuth has a higher atomic number than platinum or gold, the oxide element that presents with the bismuth had caused molecular changes and decreased the atomic number of $\mathrm{Bi}_{2} \mathrm{O}_{3}$ to a comparable platinum element $\left(\mathrm{Z}_{\text {eff }}=78\right) .{ }^{12}$ Thus, the platinum-based Cis drug had able to trigger more ROS generation when compared to the BiONPs, as another $35 \%$ of molecules within the Cis may also contribute to the escalation of intracellular ROS level. However, the in-depth mechanism is not yet been studied. The high ROS production might also occur due to the increments of other oxidative stress parameters, several types of serum, and other oxide molecules. Earlier work on chemoradiotherapy showed an increase in blood ROS levels due to elevated ceruloplasmin, albumin thiols, and malondialdehyde serum. ${ }^{71}$

Ting Guo had introduced the term of chemical enhancement (CE) for the increase of ROS production by X-rays due to the presence of NPs. ${ }^{72}$ Research by the same team on free radicals generated by gold and platinum NPs upon exposure to irradiation had demonstrated that the $\mathrm{CE}$ might lead to biological enhancement such as double-strand breakages, polymerization, and hydroxylation of DNA. ${ }^{73,74}$ One of the mechanisms associated with the CE involved the binding of NPs to the cellular repair proteins, but the cells could still function normally. However, a combination of NPs with radiations would cause the NPs to induce more ROS and cellular damages due to the repair proteins' responses inhibition. ${ }^{72}$ This CE connotation had justified the results in the current study in which the BiONPs presence in the cell samples without RT would diminish the amount of intracellular ROS when the cells were not exposed to the RT, as the maximum percentage of ROS was found to be only $92 \%$ and $88 \%$ in MCF-7 and MDA-MB-231 cells, respectively. When a dose of 3 Gy of the electron beam was given, then the ROS would accumulate to a minimum of $1496 \%$.

The CE occurrence may correlate with several processes such as the asymmetric electrical coupling and electron transfer modulation at the interfaces of the high $\mathrm{Z}$ metals with dielectric oxides, as well as the generation of electron-hole pairs after the absorption of X-rays by the NPs. ${ }^{38,72,75-77}$ BiONPs features indicated the 
characteristics of a semiconductor and a photocatalyst. ${ }^{78}$ Thus, it could react by absorbing the bandgap energy and creating the electron-hole pairs when irradiated with X-rays. ${ }^{72}$ It is proposed that the pairs transferred to the NPs surfaces and experienced the catalysis reactions or responded to the water or oxygen to form the ROS. ${ }^{72,76}$

Meanwhile, the ROS triggered by the presence of baicalein-rich fraction (BRF) in brachytherapy is intermediate between BiONPs and Control. Nevertheless, in photon and electron therapies, the ROS values for BRF are below the control level, and this condition signified the possible radioprotective activity of the BRF. The presence of BRF might activate the reduction-oxidation (redox) reaction in the cells, which might involve enzymes such as thioredoxin reductase, superoxide dismutase (SOD), catalase, and glutathione peroxidase (Gpx), thus reduce the ROS level after irradiation. ${ }^{48}$ The baicalein compound could decrease the ROS production and protecting neural progenitor cells of the brain against radiation. ${ }^{79}$ The course of actions might involve not only free radical scavenging activity but also upregulation of pro-survival transcription factors, and consequently, increase the tolerance level of the cells towards oxidative stress. ${ }^{25}$ The present findings may also be attributed to the presence of naturallyoccurring phenols and flavonoids, as well as trace metals in the plant compounds. ${ }^{80,81}$ The previous research is in agreement with the current study in which the naturalbased anti-cancer compounds carried the antioxidant and radioprotective properties. $^{82}$

While the overall magnitude of ROS triggered was less in brachytherapy compared to photon and electron beams, the gap of the ROS produced in the presence of the BiONPs, Cis and BRF, as compared to the control, were always significant in brachytherapy. Final findings highlighted that the existence of $\mathrm{Cis}$ in the cells promoted the highest chemical reactions during the brachytherapy, relative to the participation of BONPs and BRFs.

\section{Intracellular ROS Induced by Radiation with $B B, B C$, and $B C B$ Combinations}

Apart from the ROS effect from individual BiONPs, Cis, and BRF after irradiations, the effects of the three individual component combinations were also examined. The percentages of ROS stimulated by the BB or BCB were lower than the positive controls for the photon and electron beams. The results are comparable to the ROS induced by the BRF alone in the previous part of the study and strengthen the inference of the BRF acting as the radioprotector at the high energy radiations. Meanwhile, the $\mathrm{BC}$ combination had initiated the highest ROS responses. Nonetheless, it is also marked that the general ROS levels triggered by the photon beam and brachytherapy with $\mathrm{BC}$ combination were not significantly different. The situation may indicate the applicability of the $\mathrm{BC}$ combination as the radiosensitizer in both RT modalities, as well as suggest that the ROS could be intrinsically influenced by the photons, compared to the electron particles. While the charged electron particles can directly ionize the cells, photons are considered as the indirectly ionizing radiations as they induced secondary electrons. ${ }^{83}$ The energy of the secondary electrons emitted from the radiosensitizers might be incorporated back into the surrounding medium, typically in the ROS molecule forms. ${ }^{84}$

The observations established in the present study are likely related to the possible interactions among the prooxidants (BiONPs and Cis) as well as the anti-oxidant (BRF). Four different natures of interactions might occur when $\mathrm{BC}$ and $\mathrm{BB}$ combinations were tested with brachytherapy, photon, and electron irradiations; additive effects by the $\mathrm{BC}$, as well as negative synergism and positive antagonisms (from double-positive and opposing interactions) by the $\mathrm{BB}$.

The BiONPs and Cis were additively supported each other when combined, yet they did not give off the synergetic effect. Interestingly, Shakibaie et al discoveries supported this current study, in which bismuth nanoparticles possessed moderate radical scavenging properties but might also stimulate oxidative stress in facilitating cell killing mechanisms. ${ }^{85}$ In a report of irradiated $\mathrm{Bi}_{2} \mathrm{Se}_{3}$-treated mice, it was indicated that the ROS induced in the blood could be oxidized by the nanoparticles. ${ }^{86}$ The anti-radical properties of BiONPs could be instigated by the deficiency of oxygen in the material's surface, which might undergo a combination with the ROS. ${ }^{87}$ Stewart also had validated that this redox system by BiONPs is irreversible and would continue up to 48 hours only. ${ }^{87}$ Other biological points, such as components in cell culture media and the presence of naturally-occurring reducing agents in the cells, might also affect the oxidative stress within the cell system. ${ }^{88}$ Thus, the ROS levels were elevated only slightly higher than both BiONPs and Cis such as BC (1).

On the other hand, the BiONPs and BRF were negatively synergized or positively antagonized each other when mixed and irradiated. Fundamentally, these reactions occurred due to the presence of BRF that acted as radical scavengers. These reactions further confirm the conflicting roles of $\mathrm{Cis}$ and $\mathrm{BRF}$ as both are anti-cancer agents but 
have differed oxidative properties. The BRF could be comparable to a selenium-based compound, in which it was able to enhance the reduction of radical species induced by the Cis. ${ }^{63}$ The present finding is also in agreement with a previous study that mentioned the baicalein could down-regulate mitogen-activated protein kinases

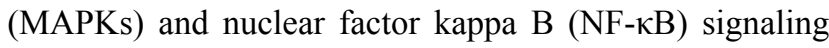
pathways, while up-regulated antioxidant mechanisms in restoring renal damages by $\mathrm{Cis}^{89}$ Baicalein also demonstrated a protective effect on keratinocytes by scavenging the ROS-induced by ultraviolet $\mathrm{B}$ radiation. ${ }^{90}$

Nevertheless, none of the $\mathrm{BB}$ and $\mathrm{BC}$ combinations interaction could possibly undergo the positive synergism, as the ROS generations by the combinations did not exceed the summation of two individual treatments. ${ }^{55,91}$ Additionally, the $\mathrm{BCB}$ combination interactions were not able to be interpreted by Piggott et al's model as it involved more than two components. Reasonably, it can be deduced that the prooxidant $\mathrm{Cis}$ and anti-radical BRF counterbalanced the intermediate level of ROS by BCB combination. Primarily, the most favorable probable interaction was the additive effect by BC (1). Thus, the present study proposed that combinations of radiation and nanomaterials, such as BiONPs and Cis, could further amplify the ROS formation in cancer cells over the time from the additive to the synergistic effect with the formula of " $1+1>2$ ". 55 This response is described as a cumulative interaction. ${ }^{92}$

The increment of ROS level may correlate to the indirect DNA damage processes attributable to apoptosis cell death mechanism, which may happen within 24 to 72 hours after irradiation. ${ }^{90,93-95}$ A previous study deduced that ROS has a role in cell cycle redistribution and the apoptosis process, involving the cellular repair system. Chen et al investigated the ROS accumulation in mitochondria and revealed that this ROS overabundance would activate caspase 3 protein, which in return disturbed the electron transport chain. ${ }^{96}$ The prolonged ROS accession would further damage the mitochondria functions and lead to the apoptotic cellular death. ${ }^{96}$ Apoptosis is highly correlated to the radiosensitization process. ${ }^{37,93,94,97-99}$

\section{Radiosensitization Effects Induced by $\mathrm{BB}, \mathrm{BC}$, and $\mathrm{BCB}$ Combinations}

The primary principle in radiotherapy is delivering a low radiation dose to normal cells while providing higher radiation doses to target cancer sites. Thus, this part of the radiosensitization study also involved normal fibroblast cell line, NIH/3T3, with other two breast cancer cells, MCF-7 and MDA-MB-231. Our recently published research had demonstrated the radiosensitization effect of BiONPs, Cis, and BC in brachytherapy. ${ }^{12}$ Subsequently, this study proposed to determine the sensitization enhancement of additional $\mathrm{BB}$ and $\mathrm{BCB}$ for brachytherapy as well as effects of $\mathrm{BB}, \mathrm{BC}$ and $\mathrm{BCB}$ for photon and electron beams.

Based on Table 2, it can be discerned that the sensitization enhancement ratio (SER) values in MCF-7 and MDA-MB-231 cells had been heightened in the presence of the three combinations in the following decreasing manner: $\mathrm{BC}, \mathrm{BCB}$ and $\mathrm{BB}$ treatments. This data is supported by the ROS productions in the previous discussion. Despite that, the SER values were contradictory to ROS formation concerning the type of cells and type of radiation beams. The ROS was higher from photon irradiation, but the electron irradiation shows more sensitization enhancement, whereas the ROS generation was higher in MDA-MB-231 cells while the SER values are more significant in MCF-7 cells.

Although MDA-MB-231 cells were more sensitive to biological components like ROS production, they might have a highly active repair system that leads to the radiation resistance and lower SER values compared to MCF-7 cells. The molecular analysis had highlighted the upregulation of 12 selected genes involved in radioresistance within irradiated MDA-MB-231 cells. ${ }^{100}$ These upregulated genes are associated with drug resistance and stem cell-like processes such as activation of cell division, RNA polymerase II promoter transcription, and protein phosphorylation as well as the binding of ATP, chromatin, and interleukin-1 (IL-1) receptor. ${ }^{100}$ Boo et al also supported the outcomes in which their study found more basal-like cellular receptors (CD44+/CD24- and ALDH +) were expressed in MDA-MB-231 compared to MCF-7 cells. ${ }^{59}$ In contrast, the high MCF-7 cells' SER values may be caused by the amplification of the expression of caspase 3 , caspase 9, and cytochrome $C$ proteins when NPs were present during irradiation that could initiate mitochondrialassociated cellular apoptosis. ${ }^{96}$ Wang and Zhang also concluded that their ROS levels did not influence the effectiveness of radiation in both cell lines. ${ }^{101}$ Likewise, the proposition of ROS as the auxiliary factor to the radiosensitization process in our previous published study ${ }^{12}$ had justified the present findings that showed contrary results between ROS output and SER values in MCF-7 and MDA-MB-231 cells. 
Extensive research on the combination of radiation and NPs as a radiosensitizer was positively established. Theoretically, a Monte Carlo simulation for 6 MV x-rays on materials with the atomic number of 25 to 90 had exhibited the dose enhancement only up to a maximum value of $1.007 .{ }^{102} \mathrm{In}$ silico simulation tests on BiONPs of various sizes, shapes and concentrations had been performed for $125 \mathrm{kVp}, 6 \mathrm{MV}, 10 \mathrm{MV}$ and different brachytherapy sources. ${ }^{9,103-107}$ Experimentally, in vitro studies also presented different SER and DEF values by BiONPs, which were influenced by the type of radiation beam, type of cell lines used, as well as the concentrations, shapes and sizes of the BiONPs. ${ }^{15,103,108}$ NPs may induce ROS formation in high amounts and lead to low survival fraction. ${ }^{15}$ The studies above may suggest that BiONPs also contribute to the sensitization enhancement caused in $\mathrm{BB}, \mathrm{BC}$, and $\mathrm{BCB}$ combinations.

On the other hand, cisplatin is a standard drug that has been used in clinical settings as one of the chemotherapeutic agents. Roles of cisplatin as a radiosensitizer are also have been evaluated in concurrent chemoradiotherapy investigations. ${ }^{109-111}$ Combination of other material with low usage of cisplatin concentration is also currently being to further increase the radiosensitization effects on target cancer cells. Cisplatin had been combined with organoselenium compound or gold NPs that results in the achievement of additive effects as well as successful enhancement of radiosensitization. ${ }^{63,112,113}$ However, there is still scarce study on the combination of cisplatin with bismuth-based nanoparticles for radiosensitization effects.

A combination of BC for brachytherapy had given the highest effect of radiosensitization, which might be caused by the synergism reaction between the individual BiONPs and Cis. ${ }^{12}$ The SER value of 4.29 is especially doubled from the SER of $\mathrm{BC}$ for photon and electron irradiations. The differences may signify the $\mathrm{BC}$ treatment is highly efficient at low-energy radiation. The findings are compatible with a series of relevant reports that have shown a relatively higher doses enhancement from radionuclide sources and low-energy $\mathrm{x}$-ray beams relative to external megavoltage beam sources. ${ }^{8,102,114}$ In comparison between photon and electron beams, the two beams are used in RT for cancers in different cases. Electron beam with energies up to $21 \mathrm{MeV}$ is usually used for superficial tumors, while the photon beam is generally applied for deep-seated tumors. ${ }^{108,115,116}$ In this study, BC treatment for electron beam radiation cause higher SER value than photon beam in MCF-7 and NIH/3T3 cell lines. This data was supported by research on the treatment of polyethylene glycol
(PEG)-coated BiONPs in MCF-7 cells, which could produce an SER value of 1.13 for electron irradiation. ${ }^{108}$ In contrast, photon beam irradiation would give an SER value of $1.12 .{ }^{108}$ However, this case was contradictory to our previous work of the uncoated-BiONPs on the MCF-7 cells, in which $6 \mathrm{MV}$ photon had been induced the SER of 1.88 while $6 \mathrm{MeV}$ generated the SER of $1.42 .{ }^{13}$ The different findings may indicate that the functionalization of BiONPs with PEG would lower the radiosensitization effects in MCF-7 cells. The presence of Cis in the BC treatment might have reacted similarly to the PEG coating. While for MDA-MB-231 cells, it was found that, in the presence of NPs, the electron beam could cause a lower SER value (1.04) than SER for the photon beam (1.29), ${ }^{117}$ which also agrees with our results on MDA-MB-231 cells.

Apart from that, this study is the first to present the radiosensitization effect of baicalein-based compound BRF in combination with other materials. The BRF in the present work is not a completely pure baicalein compound, as evaluated in other previous studies. ${ }^{79,100,118}$ Baicalein was found to protect irradiated C17.2 neural progenitor cells from necrosis through ROS rectification and upregulation of brainderived neurotrophic factor-phosphorylated cAMP response element-binding (BDNF-pCREB) pathway. ${ }^{79}$ A more recent study irradiated MDA-MB-231 breast cancer cells in the presence of baicalein compound testified the up-regulation of apoptosis-affiliated proteins such as tumor necrosis factor (TNF), nuclear factor $\kappa \mathrm{B}$ (NF- $\mathrm{kB})$, Toll-like receptor (TLR), and interferon-induced protein with tetratricopeptide repeats 2 (IFIT2) signaling pathways. ${ }^{100,118}$ They also observed the down-regulation of cellular invasion-related mRNAs, such as urokinase-type plasminogen activator (u-PA), matrix metalloproteinase 2 (MMP-2) and MMP-9. ${ }^{100,118}$ Hence, it was surmised that baicalein-rich fraction (BRF) could promote radiosensitization, but maybe with a lower capacity than BiONPs and Cis due to its anti-radical properties.

Besides, the survival curves in Figure 5 were configured with the LQ model, defining the $\alpha$ and $\beta$ values as single and double hits of DNA breakages, respectively. The survival curves revealed that the $\mathrm{BC}, \mathrm{BB}$ and $\mathrm{BCB}$ therapies had higher $\alpha$ levels, reflecting a significant amount of single radiation occurring at the early initial dose level. During radiation therapy alone (control), all $\alpha$ and $\beta$ values are positive, suggesting that both single and double-strand DNA ruptures have occurred. ${ }^{15}$ The parameter values indicate that the combination therapies are exemplary therapeutic strategies relative to regular conventional treatment. 
Furthermore, $\mathrm{BB}, \mathrm{BC}$, and $\mathrm{BCB}$ combination treatments had evoked radiosensitization enhancement in all three types of cells. However, $\mathrm{BB}$ and $\mathrm{BCB}$ treatments were perceived to sensitize $\mathrm{NIH} / 3 \mathrm{~T} 3$ normal cells more than MDA-MB-231 breast cancer cells for photon and electron beams radiotherapy. This circumstance indicates that the healthy cells near the cancer target site would be more susceptible to the radiation. Even though irradiation with the presence of $\mathrm{BC}$ could slightly increase the radiosensitivity of NIH/3T3 normal cells, it could be considered as insignificant as the side effects observed during the concurrent cisplatin chemoradiotherapy randomized clinical trials. ${ }^{110,111}$ In contrast to the $\mathrm{BC}$, the $\mathrm{BCB}$ combination could cause more detrimental effects on NIH/3T3 normal cells. Therefore, the current study hypothesized that $\mathrm{BC}$ combination is a more appropriate radiosensitizer for brachytherapy, photon and electron beams RT, in comparison to $\mathrm{BB}$ and $\mathrm{BCB}$ combinations.

\section{Conclusion}

The intracellular ROS induced in the presence of individual BiONPs, Cis and BRF were notably high in the ratio for the HDR brachytherapy. Meanwhile, the highest ROS enhancement was observed due to the presence of $\mathrm{BC}$ combination for HDR brachytherapy and 6 MV photon beam irradiation. The SER values for MCF-7 and MDA-MB-231 cells indicate that the radiosensitization effects in the presence of the compound combinations are decreasing in the following manner: $\mathrm{BC}$, $\mathrm{BCB}$, and $\mathrm{BB}$ treatments. The highest SER value was demonstrated by the presence of $\mathrm{BC}$ combination during the HDR brachytherapy. Interestingly, BCB combination also presented a high radiosensitization enhancement but collaterally affected the normal cells as well. The BiONPs-Cis (BC) shows potential as an effective radiosensitizer for clinical RT with further cellular and molecular aspects of analysis are required to elucidate the radiosensitization mechanism.

\section{Disclosure}

The authors report no conflicts of interest.

\section{References}

1. IAEA. Radiotherapy in Cancer Care: Facing the Global Challenge. Vienna; 2017.

2. Martins I, Raza SQ, Voisin L, et al. Anticancer chemotherapy and radiotherapy trigger both non-cell-autonomous and cell-autonomous death article. Cell Death Dis. 2018;9(716):1-18. doi:10.1038/s41419018-0747-y

3. WHO. Globocan 2018; 2019. Available from: https:/gco.iarc.fr/today/ data/factsheets/populations/900-world-fact-sheets.pdf. Accessed October 1, 2020.
4. Bray F, Ferlay J, Soerjomataram I, Siegel RL, Torre LA, Jemal A. Global cancer statistics 2018: GLOBOCAN estimates of incidence and mortality worldwide for 36 cancers in 185 countries. CA Cancer J Clin. 2018;68(6):394-424. doi:10.3322/caac.21492

5. Evans S, Young M, Higgins S, Moran MS. Biological basis of radiotherapy of the breast. In: Bland KI, Copeland EM, Klimberg VS, Gradishar WJ, White J editors, The Breast: Comprehensive Management of Benign and Malignant Diseases. 5th ed. Philadelphia: Elsevier Inc.; 2017:663-672.e2.doi:10.1016/ B978-0-323-35955-9.00046-5

6. Goswami N, Luo Z, Yuan X, Leong DT, Xie J. Engineering gold-based radiosensitizers for cancer radiotherapy. Mater Horiz. 2017;4(5):817-831. doi:10.1039/c7mh00451f

7. Moulder JE. Chemical radiosensitizers: the journal history. Int J Radiat Biol. 2019;1-5. doi:10.1080/09553002.2019.1569779

8. Rahman WN, Bishara N, Ackerly T, et al. Enhancement of radiation effects by gold nanoparticles for superficial radiation therapy. Nanomedicine. 2009;5:136-142. doi:10.1016/j. nano.2009.01.014

9. Taha E, Djouider F, Banoqitah E. Monte Carlo simulations for dose enhancement in cancer treatment using bismuth oxide nanoparticles implanted in brain soft tissue. Australas Phys Eng Sci Med. 2018;41(2):363-370. doi:10.1007/s13246-018-0633-z

10. Rahman WN, Davidson R, Yagi N, Bansal V, Geso M, Darby I. Influence of gold nanoparticles on radiation dose enhancement and cellular migration in microbeam-irradiated cells. Bionanoscience. 2011;1-11. doi:10.1007/s12668-011-0001-x

11. Rashid RA, Razak KA, Geso M, Abdullah R, Dollah N, Rahman WN. Radiobiological characterization of the radiosensitization effects by gold nanoparticles for megavoltage clinical radiotherapy beams. Bionanoscience. 2018;8(3):713-722. doi:10.1007/s12668-018-0524-5

12. Sisin NNT, Abdul Razak K, Zainal Abidin S, et al. Radiosensitization effects by bismuth oxide nanoparticles in combination with cisplatin for high dose rate brachytherapy. Int $J$ Nanomedicine. 2019;14:9941-9954. doi:10.2147/IJN.S228919

13. Sisin NNT, Abidin SZ, Yunus MA, Zin HM, Razak KA, Rahman WN. Evaluation of bismuth oxide nanoparticles as radiosensitizer for megavoltage. Int J Adv Sci Eng Inf Technol. 2019;9 (4):1434-1443. doi:10.18517/ijaseit.9.4.7218

14. Sisin NNT, Azam NA, Rashid RA, et al. Dose enhancement by bismuth oxide nanoparticles for HDR brachytherapy. J Phys Conf Ser. 2020;1497(012002):1-5. doi:10.1088/1742-6596/1497/1/ 012002

15. Rashid RA, Zainal Abidin S, Khairil Anuar MA, et al. Radiosensitization effects and ROS generation by high $\mathrm{Z}$ metallic nanoparticles on human colon carcinoma cell (HCT116) irradiated under $150 \mathrm{MeV}$ proton beam. OpenNano. 2019;4:100027. doi:10.1016/j.onano.2018.100027

16. Muhammad MA, Rashid RA, Lazim RM, Dollah N, Razak KA, Rahman WN. Evaluation of radiosensitization effects by platinum nanodendrites for $6 \mathrm{MV}$ photon beam radiotherapy. Radiat Phys Chem. 2018;150:40-45. doi:10.1016/j. radphyschem.2018.04.018

17. Li S, Porcel E, Remita H, et al. Platinum nanoparticles: an exquisite tool to overcome radioresistance. Cancer Nanotechnol. 2017;8(1). doi:10.1186/s12645-017-0028-y

18. Grauer O, Jaber M, Hess K, et al. Combined intracavitary thermotherapy with iron oxide nanoparticles and radiotherapy as local treatment modality in recurrent glioblastoma patients. $J$ Neurooncol. 2019;141(1):83-94. doi:10.1007/s11060-018-03005-x

19. Bonvalot S, Le Pechoux C, De Baere T, et al. First-in-human study testing a new radioenhancer using nanoparticles (NBTXR3) activated by radiation therapy in patients with locally advanced soft tissue sarcomas. Clin Cancer Res. 2017;23(4):908-917. doi:10.1158/1078-0432.CCR-16-1297 
20. Verry C, Sancey L, Dufort S, et al. Treatment of multiple brain metastases using gadolinium nanoparticles and radiotherapy: NANO-RAD, a Phase I study protocol. BMJ Open. 2019;9 (2):1-6. doi:10.1136/bmjopen-2018-023591

21. Yu Z, Zhang $\mathrm{C}$, Wang $\mathrm{H}$, et al. Multidrug resistance-associated protein 3 confers resistance to chemoradiotherapy for rectal cancer by regulating reactive oxygen species and caspase-3-dependent apoptotic pathway. Cancer Lett. 2014;353 (2):182-193. doi:10.1016/j.canlet.2014.07.025

22. Gupta S, Koru-Sengul T, Arnold SM, Devi GR, Mohiuddin M, Ahmed MM. Low-dose fractionated radiation potentiates the effects of cisplatin independent of the hyper-radiation sensitivity in human lung cancer cells. Mol Cancer Ther. 2011;10 (2):292-302. doi:10.1158/1535-7163.mct-10-0630

23. Liu M, Ma S, Liu M, et al. Synergistic killing of lung cancer cells by cisplatin and radiation via autophagy and apoptosis. Oncol Lett. 2014;7(6):1903-1910. doi:10.3892/ol.2014.2049

24. Jiang L, Iwahashi $H$. The roles of radio-functional natural chemicals for the development of cancer radiation therapy. Rev Environ Health. 2019;34(1):5-12. doi:10.1515/reveh-2018-0057

25. Patwardhan R. Amelioration of Ionizing Radiation Induced Cell Death in Lymphocytes by Baicalein [PhD]. 2015.

26. Thokchom DS, Shantikumar L, Sharma GJ. Protection of radiation-induced DNA damage in albino rats by oroxylum indicum (L.) vent. Int J Pharmacogn Phytochem Res. 2014;6 (3):514-523

27. Minafra L, Porcino N, Bravata V, et al. Radiosensitizing effect of curcumin- loaded lipid nanoparticles in breast cancer cells. Sci Rep. 2019;9(11134):1-16. doi:10.1038/s41598-019-47553-2

28. Santos FTJ, Siqueira WN, Santos MLO, et al. Radiosensitizer effect of usnic acid on biomphalaria glabrata embryos. Int $J$ Radiat Biol. 2018;94(9):838-843. doi:10.1080/ 09553002.2018.1492757

29. Malyarenko OS, Usoltseva RV, Zvyagintseva TN, Ermakova SP. Laminaran from brown alga Dictyota dichotoma and its sulfated derivative as radioprotectors and radiosensitizers in melanoma therapy. Carbohydr Polym. 2018;206:539-547. doi:10.1016/j. carbpol.2018.11.008

30. Rahman WN, Mat NFC, Long NAC, Rashid RA, Dollah N, Abdullah R. Radiosensitizing effects of oroxylum indicum extract in combination with megavoltage radiotherapy beams. In: Materials Today: Proceedings. Vol. 16. Elsevier Ltd.;2019:2072-2077. doi:10.1016/j.matpr.2019.06.094

31. Kang IN, Nik Salleh NNH, Chung WJ, et al. Baicalein-enriched fraction extracted from oroxylum indicum (L.) benth. ex kurz leaves exerts antioxidant and inhibitory effects against glioblastoma multiforme. Processes. 2019;7(12):1-16. doi:10.3390/ PR7120963

32. Wahab NH, Mat NFC. Baicalein-rich fraction of oroxylum indicum leaves induces apoptosis by repressing E6 and E7 expression in HPV-associated cervical cancer cell lines. Int J Res Pharm Sci. 2018;9(SPL2):108-117.

33. Noronha V, Patil V, Joshi A, et al. Is taxane/platinum/5 fluorouracil superior to taxane/platinum alone and does docetaxel trump paclitaxel in induction therapy for locally advanced oral cavity cancers? Indian J Cancer. 2015;52(1):70-73. doi:10.4103/0019-509X.175604

34. Somani N, Goyal S, Pasricha R, et al. Sequential therapy (triple drug-based induction chemotherapy followed by concurrent chemoradiotherapy) in locally advanced inoperable head and neck cancer patients - single institute experience. Indian $J$ Med Paediatr Oncol. 2011;32(2):86-91. doi:10.4103/0971-5851. 89781

35. Brun E, Sicard-Roselli C. Actual questions raised by nanoparticle radiosensitization. Radiat Phys Chem. 2016;128:134-142. doi:10.1016/j.radphyschem.2016.05.024
36. Wang H, Jiang H, Van De Gucht M, De Ridder M. Hypoxic radioresistance: can ROS be the key to overcome It? Cancers (Basel). 2019;11(1):112. doi:10.3390/cancers11010112

37. Alan Mitteer R, Wang Y, Shah J, et al. Proton beam radiation induces DNA damage and cell apoptosis in glioma stem cells through reactive oxygen species. Sci Rep. 2015;5(13961):1-12. doi:10.1038/srep13961

38. Cheng K, Sano M, Jenkins CH, Zhang G, Vernekohl D. Synergistically enhancing therapeutic effect of radiation therapy with radiation activatable and reactive oxygen species-releasing nanostructures. ACS Nano. 2018;12(5):4946-4958. doi:10.1021/ acsnano.8b02038

39. Zulkifli ZA, Razak KA, Rahman WNWA, Abidin SZ. Synthesis and characterisation of bismuth oxide nanoparticles using hydrothermal method: the effect of reactant concentrations and application in radiotherapy. J Phys Conf Ser. 2018;1082(1):012103. doi:10.1088/1742-6596/1082/1/012103

40. Sisin NNT, Mat NFC, Abdullah R, Rahman WN. Baicalein-rich fraction as a potential radiosensitizer or radioprotective for HDR brachytherapy: a preliminary study. Oral presentation at: Student Mini Conference10th International Conference on Isotopes; February 5; 2020; Kuala Lumpur.

41. Jaeger S, Igea A, Arroyo R, et al. Quantification of pathway cross-talk reveals novel synergistic drug combinations for breast cancer. Cancer Res. 2017;77(2):459-469. doi:10.1158/00085472.CAN-16-0097

42. Fazio E, Speciale A, Spadaro S, et al. Evaluation of biological response induced by molybdenum oxide nanocolloids on in vitro cultured NIH/3T3 fibroblast cells by micro-Raman spectroscopy. $\begin{array}{llll}\text { Colloids } & \text { Surf } \quad B \quad \text { Biointerfaces. } & 2018 ; 170\end{array}$ (December2017):233-241. doi:10.1016/j.colsurfb.2018.06.028

43. Carraher CE, Michael J, Ryan RR, Lindsey AM, Kendra M, Floyd B. Synthesis and preliminary cancer cell line results for the product of organotin dihalides and alpha-cyano-4-hydroxycinnamic acid. J Inorg Organomet Polym Mater. 2016;1-11. doi:10.1007/s10904-016-0363-1

44. Ray KJ, Sibson NR, Kiltie AE. Treatment of breast and prostate cancer by hypofractionated radiotherapy: potential risks and benefits. Clin Oncol. 2015;27(7):420-426. doi:10.1016/j. clon.2015.02.008

45. Yarnold J, Ashton A, Bliss J, et al. Fractionation sensitivity and dose response of late adverse effects in the breast after radiotherapy for early breast cancer: long-term results of a randomised trial. Radiother Oncol. 2005;75(1):9-17. doi:10.1016/j.radonc. 2005.01.005

46. Whelan TJ, Kim DH, Sussman J. Clinical experience using hypofractionated radiation schedules in breast cancer. Semin Radiat Oncol. 2008;18(4):257-264. doi:10.1016/j.semradonc.2008.04.008

47. Figueroa D, Asaduzzaman M, Young F. Real time monitoring and quantification of reactive oxygen species in breast cancer cell line MCF-7 by 2',7'-dichlorofluorescin diacetate (DCFDA) assay. J Pharmacol Toxicol Methods. 2018;94:26-33. doi:10.1016/j. vascn.2018.03.007

48. Eruslanov E, Kusmartsev S. Identification of ROS using oxidized DCFDA and flow-cytometry. In: Armstrong D, editor. Advanced Protocols in Oxidative Stress II. London: Humana Press; 2009:57-72.

49. Aranda A, Sequedo L, Tolosa L, et al. Dichloro-dihydro-fluorescein diacetate (DCFH-DA) assay: a quantitative method for oxidative stress assessment of nanoparticle-treated cells. Toxicol in Vitro. 2013;27(2):954-963. doi:10.1016/j.tiv.2013.01.016

50. Bunel V, Ouedraogo M, Nguyen AT, Stevigny C, Duez P. Methods applied to the in vitro primary toxicology testing of natural products: state of the art, strengths, and limits. Planta Med. 2014;80(14):1210-1226. doi:10.1055/s-0033-1360273 
51. Cui L. Optimization of Gold Nanoparticle Radiosensitizers for Cancer Therapy Optimization of Gold Nanoparticle Radiosensitizers [PhD]. 2016.

52. Hinwood BG. Measurement and units. In: A Textbook of Science for the Health Professions. 2nd ed. Nelson Thornes; 1997:14-15.

53. Wang H, Joseph JA. Quantifying cellular oxidative stress by dichlorofluorescein assay using microplate reader. Free Radic Biol Med. 1999;27(Nos.5/6):612-616. doi:10.1016/S08915849(99)00107-0

54. Lackmann C, Santos M, Rainieri S, et al. Novel procedures for whole organism detection and quantification of fluorescence as a measurement for oxidative stress in zebrafish (danio rerio) larvae. Chemosphere. 2018;197:200-209. doi:10.1016/j.chemosphere.2018. 01.045

55. Piggott JJ, Townsend CR, Matthaei CD. Reconceptualizing synergism and antagonism among multiple stressors. Ecol Evol. 2015;5 (7):1538-1547. doi:10.1002/ece3.1465

56. Guzmán C, Bagga M, Kaur A, Westermarck J, Abankwa D. ColonyArea: an ImageJ plugin to automatically quantify colony formation in clonogenic assays. PLoS One. 2014;9(3):14-17. doi:10.1371/journal.pone.0092444

57. Han XJ, Yang ZJ, Jiang LP, et al. Mitochondrial dynamics regulates hypoxia-induced migration and antineoplastic activity of cisplatin in breast cancer cells. Int J Oncol. 2015;46(2):691-700. doi:10.3892/ijo.2014.2781

58. Ya R, Sd H, Dc M, et al. Calibration of a pH-sensitive fluorophore permits valid optical recordings of breast cancer intracellular $\mathrm{pH}$ in MDA-MB-231 triple negative breast cancer and 22Rv1 prostate cancer cell lines. J Clin Breast Cancer Res. 2018;2(1):2-6.

59. Boo L, Ho WY, Ali NM, et al. Phenotypic and microRNA transcriptomic profiling of the MDA-MB-231 spheroid- enriched CSCs with comparison of MCF- 7 microRNA profiling dataset. PeerJ. 2017;5(e3551):1-27. doi:10.7717/peerj.3551

60. Mccauley J, Zivanovic A, Skropeta D. Bioassays for Anticancer Activities. Methods Mol Biol. 2013;1055:191-205.

61. Altundal Y, Cifter G, Detappe A, et al. New potential for enhancing concomitant chemoradiotherapy with FDA approved concentrations of cisplatin via the photoelectric effect. Phys Med. 2015;31 (1):25-30. doi:10.1097/CCM.0b013e31823da96d.Hydrogen

62. Li X, Wang H, Wang J, et al. Emodin enhances cisplatin-induced cytotoxicity in human bladder cancer cells through ROS elevation and MRP1 downregulation. BMC Cancer. 2016;16(578):1-10. doi:10.1186/s12885-016-2640-3

63. Ghosh P, Singha Roy S, Basu A, Bhattacharjee A, Bhattacharya S. Sensitization of cisplatin therapy by a naphthalimide based organoselenium compound through modulation of antioxidant enzymes and p53 mediated apoptosis. Free Radic Res. 2015;49(4):453-471. doi:10.3109/10715762.2015. 1012079

64. Narita N, Ito Y, Takabayashi T, et al. Suppression of SESN1 reduces cisplatin and hyperthermia resistance through increasing reactive oxygen species (ROS) in human maxillary cancer cells. Int $J$ Hyperth. 2018;35(1):269-278. doi:10.1080/02656736. 2018.1496282

65. Mukherjee SG, O'Claonadh N, Casey A, Chambers G. Comparative in vitro cytotoxicity study of silver nanoparticle on two mammalian cell lines. Toxicol in Vitro. 2012;26(2):238-251. doi:10.1016/j.tiv.2011.12.004

66. Rahman WNWA, Rashid RA, Muhammad M, Dollah N, Razak KA, Geso M. Dose enhancement by different size of gold nanoparticles under irradiation of megavoltage photon beam. J Sains Nukl Malays. 2018;30(2):23-29.

67. Hossain M, Su M. Nanoparticle location and material dependent dose enhancement in X-ray radiation therapy. J Phys Chem C. 2013;116(43):23047-23052. doi:10.1021/jp306543q.Nanoparticle
68. Akbarzadeh F, Khoshgard K, Arkan E, Hosseinzadeh L, Azandaryani AH. Evaluating the photodynamic therapy efficacy using 5-aminolevulinic acid and folic acid-conjugated bismuth oxide nanoparticles on human nasopharyngeal carcinoma cell line. Artif Cells Nanomed Biotechnol. 2018;46(sup3):S514S523. doi:10.1080/21691401.2018.1501376

69. Deng J, Xu S, Hu W, Xun X, Zheng L, Su M. Tumor targeted, stealthy and degradable bismuth nanoparticles for enhanced X-ray radiation therapy of breast cancer. Biomaterials. 2018;154:24-33. doi:10.1016/j.biomaterials.2017.10.048

70. Abhari F, Charmi J, Rezaeejam H, et al. Folic acid modified bismuth sulfide and gold heterodimers for enhancing radiosensitization of mice tumors to X-ray radiation. ACS Sustain Chem Eng. 2020;8 (13):5260-5269. doi:10.1021/acssuschemeng.0c00182

71. Serbanescu G, Gruia M, Bara M, Anghel R. The evaluation of the oxidative stress for patients receiving neoadjuvant chemoradiotherapy for locally advanced rectal cancer. $J$ Med Life. 2017;10(1):99-103.

72. Guo T. X-Ray Nanochemistry Concepts and Development. Lockwood DJ ed. Cham, Switzerland:Springer International Publishing;2018. doi:10.1080/0889311x.2018.1526173.

73. Lien J, Su M, Guo T. Identification of individual reaction steps in complex radical reactions involving gold nanoparticles. ChemPhysChem. 2018;19(24):3328-3333. doi:10.1002/ cphc. 201800780

74. Cheng NN, Starkewolf Z, Davidson RA, et al. Chemical enhancement by nanomaterials under X-ray irradiation. $\mathrm{J} \mathrm{Am} \mathrm{Chem} \mathrm{Soc.}$ 2012;134(4):1950-1953. doi:10.1021/ja210239k

75. Misawa M, Takahashi J. Generation of reactive oxygen species induced by gold nanoparticles under x-ray and UV Irradiations. Nanomedicine. 2011;7(5):604-614. doi:10.1016/j.nano.2011.01.014

76. Takahashi J, Misawa M. Analysis of potential radiosensitizing materials for $\mathrm{x}$-ray-induced photodynamic therapy. Nanobiotechnology. 2007;3(2):116-126. doi:10.1007/s12030008-9009-x

77. Kang Z, Yan X, Zhao L, et al. Gold nanoparticle/ZnO nanorod hybrids for enhanced reactive oxygen species generation and photodynamic therapy. Nano Res. 2015;8(6):2004-2014. doi:10.1007/s12274-015-0712-3

78. Szostak K, Ostaszewski P, Pulit-Prociak J, Banach M. Bismuth oxide nanoparticles in drug delivery systems. Pharm Chem J. 2019;53(1):48-51. doi:10.1007/s11094-019-01954-9

79. Oh SB, Park HR, Jang YJ, Choi SY, Son TG, Lee J. Baicalein attenuates impaired hippocampal neurogenesis and the neurocognitive deficits induced by $\gamma$-ray radiation. $\mathrm{Br} J$ Pharmacol. 2013;168(2):421-431. doi:10.1111/j.1476-5381.2012.02142.x

80. Sisin NNT, Suláin MD, Abdullah H. Antiproliferative, antioxidative and compounds identification from methanolic extract of passiflora foetida and its fractions. J Anal Pharm Res. 2017;6 (1):1-10. doi:10.15406/japlr.2017.06.00166

81. Ravipati AS, Zhang L, Koyyalamudi SR, et al. Antioxidant and anti-inflammatory activities of selected chinese medicinal plants and their relation with antioxidant content. BMC Complement Altern Med. 2012;12(173):1-14. doi:10.1186/1472-6882-12-173

82. Dinda B, Silsarma I, Dinda M, Rudrapaul P. Oroxylum indicum (L.) Kurz, an important Asian traditional medicine: from traditional uses to scientific data for its commercial exploitation. $J$ Ethnopharmacol. 2015;161:255-278. doi:10.1016/j.jep.2014. 12.027

83. Mondelaers W, Lahorte P. Radiation-induced bioradicals. In: De Cuyper M, Bulte JWM, editors. Physics and Chemistry Basis of Biotechnology. Netherlands: Kluwer Academic Publishers; 2001:249-276. doi:10.1007/0-306-46891-3_10

84. Guo T. Physical, chemical and biological enhancement in X-ray nanochemistry. Phys Chem Chem Phys. 2019;21 (29):15917-15931. doi:10.1039/c9cp03024g 
85. Shakibaie M, Forootanfar H, Ameri A, Adeli-Sardou M, Jafari M, Rahimi HR. Cytotoxicity of biologically synthesised bismuth nanoparticles against HT-29 cell line. IET Nanobiotechnol. 2018;12(5):653-657. doi:10.1049/iet-nbt.2017.0295

86. Zhang XD, Jing Y, Song S, et al. Catalytic topological insulator Bi2Se3 nanoparticles for in vivo protection against ionizing radiation. Nanomedicine. 2017;13(5):1597-1605. doi:10.1016/j. nano.2017.02.018

87. Stewart CAC. An Investigation into the Tailoring of Bismuth Oxide Nanoceramic with a Biomedical Application as a High $Z$ Radiation Enhancer for Cancer Therapy. 2014.

88. Guo B, Zebda R, Drake SJ, Sayes CM. Synergistic effect of co-exposure to carbon black and $\mathrm{Fe} 2 \mathrm{O} 3$ nanoparticles on oxidative stress in cultured lung epithelial cells. Part Fibre Toxicol. 2009;6(4):1-13. doi:10.1186/1743-8977-6-4

89. Sahu BD, Kumar JM, Sistla R. Baicalein, a bioflavonoid, prevents cisplatin- Induced acute kidney injury by up- regulating antioxidant defenses and down- regulating the MAPKs and NF- $\mathrm{KB}$ Pathways. PLoS One. 2015;10(7):1-19. doi:10.1371/journal. pone.0134139

90. Oh MC, Piao MJ, Fernando PMDJ, et al. Baicalein protects human skin cells against ultraviolet B-induced oxidative stress. Biomol Ther. 2016;24(6):616-622. doi:10.4062/biomolther.2016. 022

91. Currie GM. Pharmacology, part 1: introduction to pharmacology and pharmacodynamics. J Nucl Med Technol. 2018;46(2):81-86. doi:10.2967/jnmt.117.199588

92. Baskar R, Lee KA, Yeo R, Yeoh KW. Cancer and radiation therapy: current advances and future directions. Int J Med Sci. 2012;9(3):193-199. doi:10.7150/ijms.3635

93. Muschel RJ, Soto DE, McKenna WG, Bernhard EJ. Radiosensitization and apoptosis. Oncogene. 1998;17:3359-3363. doi:10.1038/sj.onc. 1202580

94. Lipiec E, Bambery KR, Heraud P, et al. Synchrotron FTIR shows evidence of DNA damage and lipid accumulation in prostate adenocarcinoma PC-3 cells following proton irradiation. $J$ Mol Struct. 2014;1073:134-141. doi:10.1016/j.molstruc.2014.04.056

95. Choi C, Son A, Lee HS, Lee YJ, Park HC. Radiosensitization by marine sponge agelas sp. extracts in hepatocellular carcinoma cells with autophagy induction. Sci Rep. 2018;8(6317):1-10. doi:10.1038/s41598-018-24745-w

96. Chen Y, Li N, Wang J, et al. Enhancement of mitochondrial ROS accumulation and radiotherapeutic efficacy using a Gd-doped titania nanosensitizer. Theranostics. 2019;9(1):167-178. doi:10.7150/thno. 28033

97. Matthews Q, Jirasek A, Lum JJ, Brolo AG. Biochemical signatures of in vitro radiation response in human lung, breast and prostate tumour cells observed with Raman spectroscopy. Phys Med Biol. 2011;56(21):6839-6855. doi:10.1088/0031-9155/56/ $21 / 006$

98. Panikkanvalappil SR, Hira SM, El-Sayed MA. Elucidation of ultraviolet radiation-induced cell responses and intracellular biomolecular dynamics in mammalian cells using surface-enhanced Raman spectroscopy. Chem Sci. 2016;7(2):1133-1141. doi: $10.1039 / \mathrm{c} 5 \mathrm{sc} 03817 \mathrm{k}$

99. Zhu JJ, Shan JJ, Sun LB, Qiu WS. Study of the radiotherapy sensitization effects and mechanism of capecitabine (Xeloda) against non-small-cell lung cancer cell line A549. Genet Mol Res. 2015;14(4):16386-16391. doi:10.4238/2015.December.9.7

100. Koh SY, Moon JY, Unno T, Cho SK. Baicalein suppresses stem cell-like characteristics in radio-and chemoresistant MDA-MB231 human breast cancer cells through up-regulation of IFIT2. Nutrients. 2019;11(3):624. doi:10.3390/nu11030624

101. Wang H, Zhang X. ROS reduction does not decrease the anticancer efficacy of X-ray in two breast cancer cell lines. Oxid Med Cell Longev. 2019;2019(3782074):1-12. doi:10.1155/2019/3782074
102. Roeske JC, Nuñez L, Hoggarth M, Labay E, Weichselbaum RR. Characterization of the theorectical radiation dose enhancement from nanoparticles. Technol Cancer Res Treat. 2007;6 (5):395-401. doi:10.1177/153303460700600504

103. Stewart C, Konstantinov K, McKinnon S, et al. First proof of bismuth oxide nanoparticles as efficient radiosensitisers on highly radioresistant cancer cells. Phys Med. 2016;32(11):1444-1452. doi:10.1016/j.ejmp.2016.10.015

104. Rajaee A, Wang S, Zhao L. Bismuth-based nanoparticles as radiosensitizer in low and high dose rate brachytherapy. Polish $J$ Med Phys Eng. 2019;25(2):79-85. doi:10.2478/pjmpe-2019-0011

105. Nezhad ZA, Geraily G, Hataminia F, Gholami S, Abtahi SMM, Ghanbari H. Investigation of the dose enhancement effect of spherical bismuth oxide nanoparticles in external beam radiotherapy. Nanomed Res J. 2020;5(1):55-62. doi:10.22034/ nmrj.2020.01.007

106. Alqathami M, Blencowe A, Yeo UJ, et al. Enhancement of radiation effects by bismuth oxide nanoparticles for kilovoltage x-ray beams: a dosimetric study using a novel multi-compartment 3D radiochromic dosimeter. J Phys Conf Ser. 2013;444:1-4. doi:10.1088/1742-6596/444/1/012025

107. Alqathami M, Blencowe A, Geso M, Ibbott G. Quantitative 3D determination of radiosensitization by bismuth-based nanoparticles. J Biomed Nanotechnol. 2016;12(3):464-471. doi:10.1166/jbn.2016.2183

108. Abidin SZ, Zulkifli ZA, Razak KA, Zin H, Yunus MA, Rahman WN. PEG coated bismuth oxide nanorods induced radiosensitization on MCF-7 breast cancer cells under irradiation of megavoltage radiotherapy beams. Mater Today Proc. 2019;16:1640-1645. doi:10.1016/j.matpr.2019.06.029

109. Shrivastava S, Mahantshetty U, Engineer R, et al. Cisplatin chemoradiotherapy vs radiotherapy in FIGO stage IIIB squamous cell carcinoma of the uterine cervix a randomized clinical trial. JAMA Oncol. 2018;4(4):506-513. doi:10.1001/jamaoncol. 2017.5179

110. Aghili M, Andalib B, Moghaddam ZK, Safaie M, Hashemi FA, Darzikolaie NM. Concurrent chemo- radiobrachytherapy with cisplatin and medium dose rate intra- cavitary brachytherapy for locally advanced uterine cervical cancer. Asian Pac J Cancer Prev. 2018;19:2745-2750. doi:10.22034/APJCP.2018.19.10.2745

111. Hashemi FA, Akbari EH, Esmati E, Esmati E. Concurrent chemoradiation with weekly gemcitabine and cisplatin for locally advanced cervical cancer. Asian Pac J Cancer Prev. 2013;14 (9):5385-5389. doi:10.7314/apjcp.2016.17.s3.287

112. Cui L, Her S, Dunne M, et al. Significant radiation enhancement effects by gold nanoparticles in combination with cisplatin in triple negative breast cancer cells and tumor xenografts. Radiat Res. 2017;187(2):147-160. doi:10.1667/RR14578.1

113. Yang C, Bromma K, Sung W, Schuemann J, Chithrani D. Determining the radiation enhancement effects of gold nanoparticles in cells in a combined treatment with cisplatin and radiation at therapeutic megavoltage energies. Cancers (Basel). 2018;10 (150):1-16. doi:10.3390/cancers 10050150

114. Shahhoseini E, Ramachandran P, Patterson WR, Geso M. Determination of dose enhancement caused by AuNPs with Xoft ${ }^{\circledR}$ Axxent ${ }^{\circledR}$ Electronic $\left(\mathrm{eBx}^{\mathrm{TM}}\right)$ and conventional brachytherapy: in vitro study. Int $J$ Nanomedicine. 2018;2018 (13):5733-5741. doi:10.2147/IJN.S174624

115. Wilkens JJ. Introduction to radiotherapy with photon and electron beams and: treatment planning from conformal radiotherapy to IMRT. In: AIP Conference Proceedings. Vol 958; 2007:63-69. doi:10.1063/1.2825834

116. Rashid RA, Dollah N, Abdullah R, Rahman WNWA. The effects of wound dressings on the dose at surface and depth of maximum dose (dmax) for photon and electron beam radiotherapy. $J$ Med Phys Biophys. 2017;4(1):103-107. 
117. Jain S, Ch B, Coulter JA, Ph D, Hounsell AR, Karl T. Cellspecific radiosensitization by gold nanoparticles at megavoltage radiation energies. Int $J$ Radiat Oncol Biol Phys. 2011;79 (2):531-539. doi:10.1016/j.ijrobp.2010.08.044.CELLSPECIFIC
118. Xi Q, Qi H, Li Y, Xi Y, Zhang L. Low frequency ultrasound combined with baicalein can reduced the invasive capacity of breast cancer cells by down regulating the expression of MMP-2, MMP-9, and u-PA. Transl Cancer Res. 2016;5 (6):838-844. doi:10.21037/tcr.2016.12.11

\section{Publish your work in this journal}

The International Journal of Nanomedicine is an international, peerreviewed journal focusing on the application of nanotechnology in diagnostics, therapeutics, and drug delivery systems throughout the biomedical field. This journal is indexed on PubMed Central, MedLine, CAS, SciSearch ${ }^{\circledR}$, Current Contents ${ }^{\circledR} /$ Clinical Medicine, $^{\circ}$
Journal Citation Reports/Science Edition, EMBase, Scopus and the Elsevier Bibliographic databases. The manuscript management system is completely online and includes a very quick and fair peer-review system, which is all easy to use. Visit http://www.dovepress.com/ testimonials.php to read real quotes from published authors. 